\title{
Impact of Ocean Model Resolution on CCSM Climate Simulations
}

Ben P. Kirtman ${ }^{1}$, Cecilia Bitz ${ }^{2}$, Frank Bryan ${ }^{3}$, William Collins $^{4}$, John Dennis $^{3}$, Nathan Hearn ${ }^{3}$, James L. Kinter ${ }^{5}$ III, Richard Loft ${ }^{3}$, Clement Rousset ${ }^{1}$, Leo Siqueira ${ }^{1}$, Cristiana Stan ${ }^{5}$, Robert Tomas $^{3}$ and Mariana Vertenstein ${ }^{3}$

${ }^{1}$ University of Miami - Rosenstiel School for Marine and Atmospheric Science

${ }^{2}$ University of Washington - Department of Atmospheric Science

${ }^{3}$ National Center for Atmospheric Research

${ }^{4}$ University of California - Berkeley

${ }^{5}$ Center for Ocean-Land-Atmosphere Studies 


\begin{abstract}
The current literature provides compelling evidence suggesting that an eddy-resolving (as opposed to eddy-permitting or eddy-parameterized) ocean component model will significantly impact the simulation of the large-scale climate, although this has not been fully tested to date in multi-decadal global coupled climate simulations. The purpose of this paper is to document how increased ocean model resolution impacts the simulation of large-scale climate variability. The model used for this study is the NCAR Community Climate System Model version 3.5 (CCSM3.5) - the forerunner to CCSM4. Two experiments are reported here. The first experiment (i.e., control) is a 155-year present-day climate simulation using a $0.5^{\circ}$ atmosphere component (zonal resolution $0.625^{\circ}$ meridional resolution $0.5^{\circ}$ ) coupled to ocean and sea-ice components with zonal resolution of $1.2^{\circ}$ and meridional resolution varying from $0.27^{\circ}$ at the equator to $0.54^{\circ}$ in the mid-latitudes. The second simulation uses the same atmospheric model coupled to $0.1^{\circ}$ ocean and sea-ice component models. The simulations are compared in terms of how the representation of smaller scale features in the time mean ocean circulation and ocean eddies impact the mean and variable climate. In terms of the global mean surface temperature, the enhanced ocean resolution leads to a ubiquitous surface warming of about $0.2^{\circ} \mathrm{C}$. The warming is largest in the Arctic and regions of strong ocean fronts and ocean eddy activity (i.e., Southern Ocean, western boundary currents). The Arctic warming is associated with significant losses of sea-ice in the high-resolution simulation. The SST gradients in the North Atlantic, in particular, are better resolved in the high-resolution model leading to significantly sharper temperature gradients and associated large-scale shifts in the rainfall. In the extra-tropics, the interannual sea surface temperature anomaly (SSTA) variability is increased with the resolved eddies, but decreases in the deep tropics (i.e., the variance of El Niño and the Southern Oscillation is reduced). Changes in global SSTA teleconnections and local air-sea feedback are also documented and show large changes in ocean-atmosphere coupling.
\end{abstract}




\section{Introduction}

There is a growing demand for environmental predictions that include a broader range of space and time scales and that include a more complete representation of physical processes. Meeting this demand necessitates a unified approach that will challenge the traditional boundaries between weather and climate science, and will require a more integrated approach to the underlying geophysical system science and the supporting computational science. One of the consequences of this unified or seamless approach is the need to explore much higher spatial resolution in weather and climate models. This is done to better resolve features, and, more importantly, because capturing the interactions between the various physical and dynamical processes demands this increase in resolution (Randall et al. 2003; Hurrell et al. 2009; Shukla et al. 2008; Brunet et al. 2010). It is also recognized that interactions across time and space scales are fundamental to the climate system itself. The large-scale climate, for instance, determines the environment for microscale (order $1 \mathrm{~km}$ ) and mesoscale (order $10 \mathrm{~km}$ ) variability which then feedback onto the large-scale climate. In the simplest terms, the hypothesis is that the statistics of microscale and mesoscale variability significantly impact the simulation of climate. In typical climate models at, say, $200 \mathrm{~km}$ horizontal resolution ${ }^{1}$, these variations occur on unresolved scales, and the micro- and mesoscale processes are parameterized in terms of the resolved variables.

Several recent studies have focused on the importance of atmospheric model resolution in the simulation of climate (May and Roeckner 2001; Brankovic and Gregory 2001; Pope and Stratton 2002; Kobayashi and Sugi 2004; Hack et al. 2006; Navarra et al. 2008; Gent et al. 2009). The reported results range from little or no change in the mean and variable climate (i.e., Hack et al. 2006) to significant differences in the cycle of EI Niño and the Southern Oscillation

\footnotetext{
${ }^{1}$ Throughout this paper, model "resolution" refers to the spacing of model grid elements.
} 
(ENSO; Navarra et al. 2008) and in sea surface temperature (SST) biases in the upwelling regions (i.e., Gent et al. 2009).

The Gent et al. (2009; hereafter G09) study is of particular relevance here and there is much discussion throughout this paper comparing the results from our simulations with the findings of G09. First, both studies used the same version of the National Center for Atmospheric Research (NCAR) Community Climate System Model (CCSM). Second, the "highresolution" model (referred to as $0.5^{\circ} \mathrm{CCSM} 3.5$ ) used by G09 is identical to the control model used here. Third, while G09 focused on atmospheric model resolution (e.g., $2^{\circ}$ vs. $0.5^{\circ}$ horizontal resolution), the emphasis here is on ocean model resolution. We enhanced the $1^{\circ}$ ocean model resolution used by $\mathrm{G} 09$ to $0.1^{\circ}$. The atmospheric component model resolution is identical (i.e., $0.5^{\circ}$ ) in all the experiments presented here.

McClean et al. (2010) and Bryan et al. (2010) were the first to examine the question of resolution dependence of simulations with CCSM that incorporated an eddy resolving ocean component $^{2}$. In particular, McClean et al. (2010) used the same version of the CCSM component models as used in this study and G09 but with approximately a $0.25^{\circ}$ horizontal atmospheric model resolution coupled to the $0.1^{\circ}$ ocean component. The coupled model was run for 20 years, and produced simulated SST that is too cold in the sub-polar and mid-latitude Northern Hemisphere, but more realistic Aghulas eddy pathways compared to ocean-only simulations at comparable resolution. Bryan et al. (2010) examined the McClean et al. (2010) simulation as well as two additional experiments separately probing the ocean and atmospheric model resolution. As in McClean et al. (2010), the Bryan et al. (2010) simulations were run for approximately 20 years. Bryan et al. (2010) focused primarily on the coupling between the lower atmosphere and the SST, and found a more realistic pattern of positive correlation between

\footnotetext{
${ }^{2}$ In common parlance, eddy-resolving models have horizontal resolution of less than $1 / 6^{\circ}$, in contrast to coarse-resolution models with $1^{\circ}$ or greater grid spacing or eddy-permitting ocean models whose resolution lies between $1 / 6^{\circ}$ and $1^{\circ}$.
} 
high-pass filtered surface wind speed and SST when the ocean component model is eddy resolving. Both of these earlier studies are viewed as predecessors for the present work. The fundamental difference is that the focus of this work is on climate variability, which requires simulations that extend well beyond 20 years.

The purpose of this paper is to document how increased ocean model resolution impacts the simulation of the large-scale climate variability. As such, we focus on relatively large-scale features - a more regional focus will be described in subsequent papers - and require simulations that are on the order of 50-100 years. The current literature provides compelling evidence suggesting that an eddy-resolving ocean component model will significantly impact the simulation of the large-scale climate, although this has not been tested to date in multi-decadal coupled simulations. For example, Minobe et al. (2008; hereafter M08) performed two highresolution AGCM simulations - one using high resolution SST and the other with degraded or smoothed SST. The ability to resolve the sharp SST gradients associated with the Gulf Stream significantly affected the large scale AGCM simulated rainfall. Maloney and Chelton (2006) examined the SST-wind stress coupling (Chelton et al. 2001) in the Coupled Model Intercomparison Project (CMIP3) database and found that the ability to capture the observed coupling degrades with degrading resolution. Bryan et al. (2010) examined wind speed-SST coupling in their high-resolution simulations and found that, over much of the globe, resolving the ocean fronts and eddies (as opposed to increased atmospheric model resolution) was required to capture the observed relationship. Jochum et al. (2007) and Roberts et al. (2009) showed that tropical instability waves (TIW) have the potential to significantly alter tropical atmospheric variability and teleconnection patterns in precipitation extending into the extratropics, and that climate models would underestimate extreme events when TIW are not taken into account. 
The remainder of this paper is organized as follows. Section 2 describes the model configuration, experimental design and the initialization of the climate simulations. Some details regarding the numerical implementation are provided as substantial innovation was required. The drift or spin-up is diagnosed in Section 3 primarily in terms of large-area-averaged quantities. Section 4 presents global maps of the annual mean and the annual cycle along the equator. Here we focus on a 50 -year period after the simulation appears to have reached equilibrium - as measured by global mean surface temperature. We do not necessarily assert that the deep ocean has reached equilibrium. The impact of the increased ocean resolution in terms of interannual variability and air-sea interactions is discussed in Sections 5 and 6 and concluding remarks are given in Section 7.

\section{Model Configure and Experimental Design}

\section{a. CCSM3.5}

The model used for this study is the NCAR Community Climate System Model version 3.5 (CCSM3.5) (Neale et al. 2008; G09). The atmospheric component model, the Community Atmospheric Model (CAM) is based on a finite volume discretization rather than the spectral discretization of the governing equations used in earlier versions of CAM, and has extensive changes in the parameterization of sub-grid-scale processes that have resulted in a significant improvement in the simulation of tropical variability relative to CCSM3.0 (Neale et al. 2008). Changes in the other component models, while less extensive, have also contributed to a reduction in systematic biases (Jochum et al. 2008; G09).

All the component models communicate via the CCSM flux coupler (Craig et al. 2005). Fluxes at the air-sea interface are calculated at 6-hour intervals using atmospheric state variables interpolated onto the ocean model grid, and conservatively remapped back onto the other component model native grids. In all the experiments described here, the surface stress is 
computed from the relative motion of the surface atmospheric winds and ocean currents. This provides an additional potential feedback process between ocean mesoscale variability and low level atmospheric flow (e.g., Small et al. 2009), though we do not address this issue here.

\section{b. Increasing the Ocean Model Resolution}

As noted in the introduction, the objective of the numerical experiments is to examine how resolved ocean fronts and eddies impact the large-scale climate. Two experiments are reported here. The first experiment (i.e., control, referred to as LRC) is a 155-year present-day climate simulation of the $0.5^{\circ}$ atmosphere (zonal resolution $0.625^{\circ}$, meridional resolution $0.5^{\circ}$ ) coupled to ocean and sea-ice components with zonal resolution of $1.2^{\circ}$ and meridional resolution varying from $0.27^{\circ}$ at the equator to $0.54^{\circ}$ in the mid-latitudes on a dipole grid (Murray, 1996) with 60 vertical levels. This control experiment is identical to the "high-resolution" experiment in G09 in terms of the model configuration, but differs in its initial state and climate forcing. The G09 experiment was a transient climate simulation initialized with a state extracted from a coarser resolution $20^{\text {th }}$ century integration at year 1980 . The initial condition for our experiments was taken from the end of a previously completed present day control simulation carried out with an earlier version of CCSM, so that the ocean state is fully "spun-up" and the initialization shock ought to be minimized; however, as will be shown, some climate drift is apparent. The second simulation is carried out in two phases with the same atmospheric model coupled to $0.1^{\circ}$ ocean and sea-ice component models. The ocean model configuration in this case is identical to that used in a century-long ocean simulation (Maltrud et al. 2010) and in the coupled climate simulation of McClean et al. (2011). In addition to the change in horizontal resolution from the control experiment, there are commensurate changes in the parameterization of horizontal sub-grid scale dissipation, and a different, 42 level vertical grid. The lower vertical resolution in the thermocline as compared to the control experiment complicates some aspects of the comparison, but was chosen based on the degree of 
experience with this configuration. The initial condition for the first phase (referred to as $\mathrm{HRC03)}$. is the same as the control simulation except that the ocean state has been interpolated to the $0.1^{\circ} \mathrm{grid}$. This interpolation leads to a significant period of adjustment (see below). The second phase (referred to as HRC06) begins at year-102 of HRC03 using the same resolution and parameters except in this case the polar winds have been filtered to reduce computational instability. This phase of the experiment extends to year-155. A detailed comparison of the overlapping 10-year period in $\mathrm{HRC0} 3$ and $\mathrm{HRC06}$ indicates that the polar filter has minimal impact on global mean statistics and on the climate of the tropics, sub-tropics and mid-latitudes. No polar filter was applied to LRC. There are some notable differences in the polar latitudes. The analysis herein (except for documenting the spin-up) focuses on the 50 years of overlap between HRC06 and LRC.

\section{Spin-Up}

Figure 1a shows the global mean SST anomaly (averaged over grid-boxes whose ocean fractional coverage is greater than $50 \%$ ) from the beginning of the simulation to the end of year155. The anomaly is defined as the difference from the monthly mean climatology calculated from the last 50 years of each respective simulation. The LRC simulation shown in red includes all 155 years, whereas HRC03 extends from year-1 to year-112 (shown in solid black), and HRC06 (shown in blue) includes years 102 to 155 . The last 50 -year monthly climatology is shown in Fig. 1b. Here we omit HRC03 since the differences between HRC06 and HRC03 are very small. Despite the fact that the initial conditions are drawn from the same data there is a significantly different initial evolution in the LRC and HRC03 simulation. Beyond about year-50, both LRC and HRC03 appear to have similar statistics in the global mean SST variability despite rather different mean climates. Figure 1a also indicates that HRC06 and HRC03 have similar climates. Finally, we see that the annual cycle for HRC06 (or equivalently HRC03) is about $0.2-0.3^{\circ} \mathrm{C}$ warmer than LRC (Fig. 1b). This is in contrast to G09 where the increase in 
atmospheric resolution leads to upper-ocean cooling of about the same magnitude. Essentially, much of the global cooling due to increased atmospheric resolution in G09 (see their Fig. 2) is reversed by increasing the ocean resolution. Finally, we note that both simulations are considerably warmer the observational estimates from AVHRR.

\section{Annual Mean and Annual Cycle}

Figure 2a shows the annual mean SST (fractional land and sea ice coverage less than $50 \%$ in a grid cell) difference between HRC06 and LRC01. The HRC06 SST is warmer than LRC01 throughout the extra-tropics. The relative warmth of HRC06 is quite large in the North Atlantic, and is also concentrated in the western boundary current regions and the Southern Ocean. A similar response to increasing ocean component resolution was obtained in the U.K. HiGEM model (Shaffrey et al, 2009). Much of the warming along the North Atlantic Current is a result of a westward shift of the subpolar front to a more realistic position, resulting in an amelioration of the large negative SST bias typical of coarse resolution models in that region. There are large positive differences in Arctic in Fig. 2a, especially where sea ice concentrations approach $50 \%$. Figure $2 \mathrm{~b}$ shows the annual mean SST differences in a detailed view of the tropical Pacific. Here we also see ubiquitous warming, but the magnitude of the warming is generally between $0.25-0.75^{\circ} \mathrm{C}$. The tropical Pacific SST warming is largest in the vicinity of the Inter-Tropical Convergence Zone (ITCZ), which is consistent with enhanced rainfall (see Fig. 4).

The annual mean surface temperature (fractional land and sea ice coverage greater than $50 \%$ in a grid cell) is shown in Fig. 3a. This corresponds to land temperatures and regions where sea-ice coverage is greater than $50 \%$. One might expect that the land surface response would be relatively small since only the ocean resolution is different. Nevertheless, the relative warmth of the land surface in much of the Northern Hemisphere exceeds $1.0^{\circ} \mathrm{C}$. This is consistent with the results of Deser et al. (2010) who found that heat released from the Arctic 
Ocean under reduced sea-ice conditions is communicated to the Arctic atmospheric boundary layer by transients. The warming of the Southern Hemisphere land surface is limited except in Antarctica. The warming in the sea-ice regions is notable. Much of the surface where there should be perennial Arctic sea ice in the HRC06 simulation is over $5.0^{\circ} \mathrm{C}$ warmer than LRC. Sea-ice issues are discussed further below.

Figure $3 \mathrm{~b}$ shows the atmospheric temperature difference at $850 \mathrm{hPa}$. Throughout the entire lower troposphere HRC06 is warmer than LRC. This relative warmth holds even over regions where some surface cooling was noted, e.g., regions in the Southern Ocean centered on $60^{\circ} \mathrm{S}$ (see Fig. 2a). The regions of relatively large surface warming are associated with corresponding lower tropospheric warming.

The annual mean precipitation difference (HRC06-LRC) is shown in Fig. 4a. In the extratropics, the rainfall increases with increasing ocean model resolution in the regions overlying western boundary currents and the Southern Ocean near South Africa, with the largest signal over the Gulf Stream. This is consistent with regions of relatively large western boundary current temperature differences, as shown in Fig $2 \mathrm{a}$ - again with the largest temperature differences over the Gulf Stream. These large rainfall and SST differences are consistent with the AGCM experiments driven by fine-scale versus smoothed SST described by M08. The precipitation in HRC06 increases over LRC in high-latitude ice regions where HRC06 is relatively warm (see Fig. 2a). The largest precipitation differences are in the tropical Pacific. The rainfall increases in the central and eastern Pacific just north of the equator, and there is reduced rainfall in the western Pacific just north of the equator. This is consistent with an intensification and slight southward shift of the eastern Pacific ITCZ and a weakening of the northern branch of the ITCZ in the western Pacific. The east-west dipole in the rainfall differences just south of the equator in the central and western Pacific is associated with a reduction of the eastern extension of the South Pacific Convergence Zone (SPCZ) and an 
intensification of rainfall on the far western edge of the SPCZ. Interestingly, over the ocean in the equatorial Maritime Continent region, there is a relatively large reduction in rainfall associated with the increase in ocean resolution. Finally, there are some regional differences over land that are worth noting. For example, the rainfall over equatorial South America is reduced, and there is a notable increase in rainfall in the Indian summer monsoon region. The increased rainfall over peninsular India during the monsoon season is apparent in the JJAS mean rainfall difference shown in Fig. 4b.

The mechanism for the intensification and the southward shift of the east Pacific ITCZ is not fully understood, but one possible mechanism is related to the sea-ice changes (see also section 5). HRC06 has significantly less sea-ice compared to LRC in the Northern Hemisphere, which as suggested by Chiang and Bitz (2005), should lead to an equatorward shift of the ITCZ in the Northern Hemisphere as detected in Fig. $4 a$ in the eastern Pacific. It is also possible that resolved TIW in HRC06 produce relative SST warming just slightly north of the equator (Fig. 2b), which serves to shift the ITCZ equatorward (see the discussion of Fig. 6). The mechanism for the enhanced monsoon rainfall (Fig. 4b) remains an open question, but could be related to large scale shifts in the mean rainfall in the tropical Pacific.

One of the key motivating factors for this study is to assess how resolved ocean fronts and eddies impact the mean large-scale climate, through mechanisms described, for example, by M08. We have applied some of the M08 diagnostic methods in Fig. $5 a-c$, and the reader is encouraged to consult M08 for comparisons with the observational estimates. Specifically, Fig. 5a shows the North Atlantic SST climatology from HRC06 (shaded) and LRC superimposed (black contours). Fig. $5 \mathrm{~b}$ is in the same format, except the figure shows the climatological rainfall, and Fig. $5 \mathrm{c}$ shows the surface current speed calculated from monthly means. In terms of the surface temperature, HRC06 produces much sharper gradients than LRC along the coast of North America and in the Gulf Stream separation region (see Fig. 5c). Comparisons with Fig. 
2 from M08 highlight the fact that the HRC06 simulation is far more realistic even in the detailed structure to the south and east of Newfoundland. In contrast, the SST in the LRC simulation is strikingly similar to the smoothed (and degraded SST) used in the prescribed SST AGCM simulations (M08). Note that fields plotted in both Figs. 5a and 5c are on the AGCM grid, which is the same in HRC06 and LRC.

Figure 5b, also to be compared with Fig. 2 in M08, indicates significant structural changes in the simulated rainfall associated with ocean model resolution. For example, the axis of maximum rainfall in $\mathrm{HRC06}$ follows the maximum SST gradient so that the rainfall hugs the US coast and extends out into the open Atlantic as part of the Gulf Stream extension. The LRC simulation captures some aspects of the rainfall maximum along the US coast, but perhaps as expected, fails to capture the east-west oriented maximum along the Gulf Stream extension. Rainfall in the HRC06 simulation bears a striking resemblance to the high resolution AGCM simulation in M08 (their Fig. 2b) and the observational estimates (M08, Fig. 2a).

Finally, following the presentation of observed estimates of surface currents in M08 (their Fig. 1e), Fig. 5c shows the surface current speed in HRC06 (shaded) and in LRC (contours). The surface current speed is calculated from monthly mean data using the same overlapping $50-y r$ period. The improvements in the structure and amplitude of the surface current speed are striking. The Gulf Stream separation in HRC06 is easily detected and extends well into the open ocean, whereas in LRC the coastal currents are weak and less than $20 \mathrm{~cm} \mathrm{~s}^{-1}$ in broad regions where the HRC06 currents are twice as strong. Many of the complexities of the currents in the Labrador Sea and immediately to the south in the HRC06 simulation have clear analogues in the observational estimate of M08. These structural details are absent in LRC.

We have made similar figures for the Kuroshio, and while the similar changes in the currents were noted, only relatively small differences in the rainfall and SST gradients were 
detected (see Figs. 2a and 4a). This suggests that coarser ocean model resolution in LRC is sufficient to capture the broader mean SST gradient in this region, leading to only modest changes in the rainfall. However, the variability and the air-sea feedbacks are significantly altered by the differences in resolution (see Section 6).

In much the same way that resolving ocean mesoscale fronts and eddies motivated the numerical experiments presented here, resolving TIW was also expected to modify the near equatorial climate. Jochum and Murtugudde (2004), for example, argue that the presence of TIW leads to a net heat gain slightly poleward of the equator. Relative warming just north of the equator has been detected in HRC06 in both the Pacific (Fig. 2b) and to a lesser degree in the Atlantic (not shown). In order to examine the possible role of TIW, the near-equatorial (e.g., equator to $5^{\circ} \mathrm{N}$ ) annual cycle of SST difference between HRC06 and LRC is shown in Fig. 6 a. The HRC06 simulation is generally warmer than the LRC simulation throughout the year, but there is a notable increase in the relative warmth during the peak cold-tongue season (August through November) in the Pacific, which migrates westward through the early boreal winter. This peak cold tongue season is precisely when the TIW are preferentially excited. The warmer temperatures are consistent with enhanced rainfall (see Fig. 4a) and there is likely a positive feedback. Ultimately, both the sea-ice mechanism (i.e., Chiang and Bitz 2005) and the relative warming north of the equator due to the TIW are consistent with the differences (HRC06-LRC) in the tropical Pacific mean climate. Moreover, the differences in the annual cycle of the rainfall (Fig. 6b) indicate a complex response.

The increase in horizontal ocean resolution could also lead to changes in the ocean thermal structure. Here we focus on the near equatorial ocean stratification. Figure 7a-c shows the annual mean ocean temperature averaged from $1 \mathrm{~S}-1 \mathrm{~N}$ to a depth of $550 \mathrm{~m}$ for HRC06 and LRC for selected regions in each basin. Overall, the differences between HRC06 and LRC are fairly modest. The dominant difference (i.e., HRC06 vs. LRC), at least in the Pacific and Indian 
Oceans, is a warmer mixed-layer (although the depth is about the same), warmer thermoclines and colder temperatures below the core of the thermocline. This implies an increase in the upper ocean stratification in HRC06 compared to LRC. The temperature contrast across the various basins does not appear to be sensitive to the resolution. For example, both HRC06 and LRC capture similar contrasts between the warm pool (135E) and the cold tongue $(110 \mathrm{~W})$ in the Pacific and a similar lack of east-west gradient in the Indian Ocean. In the western Atlantic $\left(40^{\circ}\right.$ W), the mixed-layer and upper thermocline (e.g., above $20^{\circ} \mathrm{C}$ ) have similar structures in HRC06 and LRC. Below the core thermocline HRC06 is warmer than LRC. In the eastern Atlantic (0), both the upper and lower core of the thermocline in HRC06 is warmer and deeper than LRC with a small region of colder temperatures in $\mathrm{HRC06}$ at around $130 \mathrm{~m}$. While these changes in the annual mean stratification are modest, there are some notable differences in the variability that are discussed in Section 6. This comparison is complicated by the change in the ocean model vertical resolution between HRC06 and LRC. In general, HRC06 does not represent the strong gradients in the upper 100-200 m (particularly at 110W, 0E). At this depth LRC has better vertical resolution.

\section{Sea-Ice}

The horizontal resolution of the sea-ice model is equivalent to that of the ocean model in HRC06 and LRC. As a consequence, significant changes in the sea-ice climatology would be expected. Here we document the changes in the sea-ice for both the Arctic and the Antarctic at the two extremes of the annual cycle (i.e., March and September). The results for the Arctic are shown in Fig. 8a-d and include the sea-ice concentrations from HRC06 and LRC. In the same format, the results for the Antarctic are plotted in Fig. 9a-d. At both extremes the Northern Hemisphere (Fig. 8a and 8b) sea-ice area is considerably smaller in the HRC06 simulation compared to LRC. This relative decrease is most notable in March in the Nordic Seas extending into the Barents and Laptev Seas and in September in the central Arctic. In these regions LRC 
agrees more favorably with current sea ice observations (e.g., Comiso 1999). Sizable decreases are also seen in March in the Bering Sea and the Sea of Okhotsk, but in this case, HRC06 compares more favorably with observations, while LRC is too extensive.

A primary reason for the lack of sea ice in the Atlantic sector and central Arctic in HRC06 compared to LRC is the relatively higher ocean heat transport into the Nordic Seas and Arctic in HRC06. Interestingly transport of the mean temperature by the mean currents is the key difference, rather than by eddies. The details of this analysis will be presented in a future publication.

In the Southern Hemisphere, during both the annual minimum (March; Fig. 9a-b) and the annual maximum (September; Fig. 9c-d), the sea-ice concentrations are slightly smaller in the HRC06 simulation. Thus the relative reduction in the Southern Hemisphere is much less than in the Northern Hemisphere. In other words, the relative lack of Arctic sea-ice but comparable Antarctic sea ice in the HRC06 compared to LRC simulations is a striking hemispherically asymmetric difference between the two runs. The lack of Arctic sea ice occurs with strong Arctic warming that reaches all the way to the tropics in HRC06 compared to LRC and is consistent with the southward shift of the ITCZ in the tropical Pacific noted earlier (see also Chiang and Bitz 2005).

\section{Interannual Variability}

The previous sections have focused primarily on the mean climate. Here we briefly address the issue of how higher ocean model resolution impacts the seasonal-to-interannual variability. In this respect, we concentrate on the variability of monthly mean SST anomalies (SSTA). Figure 10a, for example, shows the ratio of the SSTA monthly standard deviation for HRC06 compared to LRC. The standard deviation is calculated on the atmospheric model grid. The SST variability applied to the atmosphere is clearly enhanced in HRC06 throughout most of 
the mid-latitudes and the subtropics. The core regions of substantially enhanced variance include the Northern Hemisphere western boundary current zones and the Southern Ocean from the Atlantic coast of South America extending through to the Pacific side of the Australian continent. The enhanced variance in these regions is to be expected, and in Figs. 12 and 13 we show evidence that the enhance variability is, in fact, interacting with the atmosphere.

In contrast to the extra-tropics, throughout most of the tropical ocean there is a reduction of variance in the eddy-resolving simulation (HRC06). Figure $10 \mathrm{~b}$ indicates that there is a robust reduction of variability in the tropical Pacific. There are two aspects to this reduction of variance that are of particular interest. First, there is a nearly uniform reduction along the equator of $0.2^{\circ} \mathrm{C}$ in the ENSO-related standard deviation. We hypothesize that the reduction of ENSO variance is an indirect effect of the ubiquitous ocean surface warming (see Fig. 2b) and modest increases in ocean stratification in the Pacific that ultimately lead to a small reduction in the ENSO variance (similar to the CCSM response to doubled $\mathrm{CO}_{2}$ levels - see Collins et al. 2010). This reduced ENSO variability leads to reduced variance in the tropical Indian Ocean and the north tropical Atlantic via well-known teleconnections.

The second aspect of interest in the reduction of variance in Fig. 10b appears as a subtle feature; namely, the standard deviation in $\mathrm{HRCO} 6$ in the western Pacific between $140^{\circ} \mathrm{E}$ and $160^{\circ} \mathrm{E}$ has a pronounced plateau compared to LRC. This is a distinctly positive aspect of the HRC06 simulation compared to the observed variance shown in Fig. 10b. For instance, most current coupled models produce ENSO variance that extends too far into the western Pacific leading to ENSO teleconnections that have the wrong sign in the western Pacific (see discussion of Fig. 11 below). Kirtman and Vecchi (2010), Wu and Kirtman (2007) and Wu et al. (2007) argue heuristically that the excessive variance and teleconnection errors are due to "excessive coupling" between the atmosphere and the ocean. Moreover, Kirtman and Vecchi (2010) described a numerical experiment in which, by adding noise to the coupled system, they 
were able to reduce this coupling in the western Pacific. The enhanced ocean resolution in HRC06 has a similar effect of adding relatively high frequency noise (see Fig. 10c) to the coupled system and destructively interfering with the excessive coupling.

Figure 10c shows the high pass filtered SSTA standard deviation along the equator for 10-years of daily data from LRC and HRC06 respectively. Only 10-years of daily data was available for this calculation. The high pass standard deviation is larger for HRC06 compared to LRC indicating that the eddies are enhancing the variance but primarily at sub-monthly time scales.

The changes in the ENSO SSTA teleconnection alluded to above are shown in Fig. 11a. Here we show the point correlation between the NINO3.4 monthly SSTA ${ }^{3}$ and the SSTA everywhere else. Fig. 11a shows the difference (HRC06-LRC) in the correlation (shaded) and Fig. $11 \mathrm{~b}$ is the correlation for HRC06 alone. The dominant features of this ENSO teleconnection are well known (Fig. 11b). There is a region in the eastern and central Pacific with a positive correlation and there are negative correlations in the western Pacific that extend in a horseshoeshaped pattern into the extra-tropics. Most coupled models, as with both HRC06 and LRC, fail to capture the spatial extent of the negative correlation in the North Pacific. There are also observed positive correlations in the north tropical Atlantic.

The difference in the correlation teleconnection (Fig. 11a) has several features that are noteworthy. For example, in the region including the north Indian Ocean, Bay of Bengal and Philippine Sea, the HRC06 simulation has higher positive correlation, which is associated with a somewhat stronger ENSO-monsoon teleconnection (not shown). In the Southern Ocean just below Australia there is a broad region of positive correlation difference. This positive increase may be viewed as reducing the erroneous negative correlation in LRC. The reduced correlation

\footnotetext{
${ }^{3} \mathrm{NINO} 3.4$ is defined as the average SSTA in the region bounded by $5^{\circ} \mathrm{N}$ to $5^{\circ} \mathrm{S}$, from $170^{\circ} \mathrm{W}$ to $120^{\circ} \mathrm{W}$.
} 
in the central South Pacific is also somewhat of an improvement, but it remains too weak and is shifted south. The positive correlation in the south tropical Atlantic in HRC06 is slightly too strong compared to observational estimates, but is of the wrong sign in LRC and hence the strong shaded differences seen in Fig. 11a. Finally, the v-shaped decrease in the correlation in the tropical far western Pacific is an overall improvement, and is associated with the reduced westward extension of the HRC06 ENSO events, but the negative correlation still remains weak compared to observational estimates.

As additional support for our assertion that the coupled processes have been altered in the western Pacific by resolving the ocean eddies, we show in Fig. 12a and $12 \mathrm{~b}$ the correlation with NINO34 as in Fig. 11, but in this case for the ocean temperature as function of depth. First, focusing on the Pacific, the overall structure of the correlation is fairly similar. For example, both HRC06 and LRC have positive correlation in the east extending to a depth of about $400 \mathrm{~m}$. In the west, both simulations have negative correlation at depth. There are, however, significant differences in the correlation. For example, at depth (200-350 m), the west Pacific negative correlation is stronger in LRC, but in the upper $100 \mathrm{~m}$ the negative correlation is considerably stronger in $\mathrm{HRC}$. This is precisely the same region where we saw enhanced negative correlation in Fig. 11 and a distinct plateau in the SSTA variance in Fig. 10b. Below $400 \mathrm{~m}$ in the west Pacific, HRC06 indicates stronger positive correlation compared to LRC.

There are also overall similarities in the Indian Ocean; particularly in the upper $150 \mathrm{~m}$. In contrast, below 150 m there are large-scale differences. For instance, the HRC06 simulation has stronger positive correlation below $150 \mathrm{~m}$ in the central and eastern Indian Ocean and very weak negative correlation in the western Indian Ocean. Much like the Indian Ocean, the Atlantic correlations in HRC06 and LRC are similar in the upper $150 \mathrm{~m}$. Differences emerge at depth. Between 200 and 250 m HRC06 is positively correlated with NINO34 SSTA, whereas this 
feature is at about $105-150 \mathrm{~m}$ in LRC. This shift in the response is consistent with the changes in the stratification seen in Fig. 7c.

To examine the changes in air-sea feedbacks we have adopted the analysis first suggested by Barsugli and Battisti (1998) and von Storch (2000) that was later applied to coupled models by Kirtman and Vecchi (2010) and Wu et al. (2006). These papers argue that, to first order, when the local point-by-point regression between the heat flux (sum of latent heat flux and sensible heat flux, such that the heat flux is positive downward, by convention) and the SSTA is strongly positive, the SST variability can be viewed as strongly forced by atmospheric variability. Conversely, when the ocean forcing dominates, the regression is negative. In computing these local regressions we seek to assess whether the changes in ocean model resolution significantly alter the coupled air-sea feedbacks. Figures 13 and 14 show the local point-by-point regression between SSTA and heat flux as a function of the annual cycle for HRC06 (Fig. 13) and LRC (Fig. 14). The regressions are presented as a function of season. The dominant overall difference is that the ocean forcing of the atmosphere (i.e., enhanced blue colors) is considerably stronger in HRC06.

On closer inspection, this enhanced ocean forcing of the atmosphere in the extra-tropics is largely associated with regions of enhanced SST variance (see Fig. 10a) and enhanced mean rainfall (see Fig. 4a). Essentially, the enhanced/resolved ocean eddy activity forces enhanced atmospheric variability. As noted in section 3, mean precipitation and SST differences are consistent with one another in that regions of enhanced mean mid-latitude rainfall coincide with large positive temperature differences associated with the western boundary currents. Some of the enhanced mean rainfall in these regions may also be the result of greater temporal SST variability along with stronger coupling between the SST variability and latent heat flux - with the ocean forcing the atmosphere - in the HRC06 compared to LRC simulation. When the ocean is driving an atmospheric response, a warm SST anomaly is associated with a larger increase in 
latent heat flux than the decrease in latent heat flux associated with a cold SST anomaly of the same magnitude because of the non-linear relationship between temperature and saturation vapor pressure. The result is a net mean increase in the flux of moisture into the atmosphere in the HRC06 simulation. A similar argument applies to stationary, spatial variability in the SST fields. In the tropics, the differences between HRC06 and LRC are relatively small as expected from the differences in the SSTA variance.

\section{Summary and Concluding Remarks}

The objective of the numerical experiments presented here was to examine how resolved ocean fronts and eddies impact the large-scale climate. To do this we examined two simulations of CCSM3.5. In the first simulation (LRC) the $0.5^{\circ}$ atmosphere was coupled to ocean and sea-ice components with zonal resolution of $1.2^{\circ}$ and meridional resolution varying from $0.27^{\circ}$ at the equator to $0.54^{\circ}$ in the mid-latitudes. In the ocean eddy resolving simulation (HRC06), the same atmosphere was coupled to $0.1^{\circ} \mathrm{C}$ ocean globally. The results described here present an overall view of the simulations, and serve to encourage more detailed studies. Nevertheless, there are some notable climatic impacts, for example:

(i) The high-resolution simulation is ubiquitously warmer than the low-resolution simulation. The largest differences are in the Arctic with notable losses of seaice and in regions of relatively large ocean eddy activity (i.e., Southern Ocean and western boundary currents). Perhaps, warming in regions of strong ocean fronts can be understood in terms of intensification and shifts of major ocean currents, but the ubiquitous warming is unexplained.

(ii) The SST front associated with the Gulf Stream is better resolved in the highresolution simulation. This leads to large structural changes in the mean rainfall. Similar changes in the currents are seen in the vicinity of the Kuroshio, 
but the increased ocean resolution is apparently not as important for maintaining the SST gradient, as the temperature and rainfall differences are small compared to the Gulf Stream.

(iii) There are large-scale robust changes in the tropical rainfall. These changes are associated with an intensification of the northern branch of the InterTropical Convergence Zones (ITCZ) in the eastern Pacific and the western Atlantic, and a small reduction of the erroneous southern ITCZ in these regions.

(iv) As expected, the variability of monthly mean SSTA increases with increasing ocean resolution throughout the extra-tropics. This increase is most notable in the western boundary current regions and the Southern Ocean. Unexpected was the decrease in ENSO variability and some of the associated tropical SSTA teleconnections (e.g., Fig. 11 tropical Atlantic).

(v) The structure of the SSTA variability along on equator in the western Pacific also showed distinct differences between HRC06 and LRC. There was a distinct plateau in the variability HRC06 that is consistent with reduced coupling and ENSO events that do not extend as far to the west as in the case of LRC. Structural changes were also detected at depth.

(vi) There were noted differences in local air-sea interactions. In the extra-tropics the strength of the coupling to the atmosphere is significantly increased with the resolved eddies. In fact, in the lower resolution simulation, the coupling is very weak.

In this paper, we have specifically avoided a detailed comparison with observational estimates. This choice was based on the recognition that, for such a high-resolution model, it is 
not feasible to re-evaluate or re-calibrate the various physical parameterizations in the component models in response to the increased resolution. We focused on how the resolved eddies impact simulation without any changes to the parameterizations - we take it for granted that significant effort is still required to ensure that the model with increased resolution can be further refined to produce improved simulations. In fact, we hope these simulations can be used to guide just such an effort.

\section{Acknowledgements:}

We acknowledge the support of the National Science Foundation (J. Kinter and C Stan through AGS 0830068 and OCI 0749290; B. Kirtman through OCl 0749165, AGS 0754341 and AGS 0850897; C. Bitz through ARC 0938204; F. Bryan, J. Dennis, N. Hearn, R. Loft, R. Tomas and M. Vertenstein through its support of NCAR). B. Kirtman also acknowledges support from the NOAA NA08OAR3420889. Computing resources were provided by the National Institute of Computational Sciences at the University of Tennessee through an award made by the TeraGrid Resource Allocations Committee.

\section{References}

Barsugli JJ, Battisti DS (1998) The basic effects of atmosphere-ocean thermal coupling on midlatitude variability. J Atmos Sci 55:477-493

Brankovic C, Gregory D (2001) Impact of horizontal resolution on seasonal integrations. Clim Dyn 18:123-143. doi:10.1007/s003820100165

Brunet, G., and Coauthors, 2010: Collaboration of the Weather and Climate Communities to Advance Subseasonal-to-Seasonal Prediction. Bull. Amer. Meteor. Soc., 91, 1397-1406.

Bryan, F. O., R. Tomas, J. M. Dennis, D. B. Chelton, N. G. Loeb, J. L. McClean, 2010: Frontal Scale Air-Sea Interaction in High-Resolution Coupled Climate Models. J. Climate, 23, 62776291. doi: 10.1175/2010JCLI3665.1

Chelton, D.B., S.K. Esbensen, M.G. Schlax, N. Thum, M.H. Freilich, F. J. Wentz, C.L.

Gentemann, M.J. McPhaden and P.S. Schopf, 2001: Observations of coupling between surface wind stress and sea surface temperature in the eastern Tropical Pacific. J. Climate, 4, 1479-1498.

Chiang, J. C. H., C. M. Bitz, 2005: Influence of high latitude ice cover on the marine intertropical convergence zone. Clim., Dyn., DOI: 10.1007/s00382-005-0040-5.

Collins, M., and co-authors, 2010: The impact of global warming on the tropical Pacific Ocean and El Nino. Nature Geoscience 3, 391-397. 
Comiso, J. 1999, updated 2008. /Bootstrap Sea Ice Concentrations from Nimbus-7 SMMR and DMSP SSM/I/, [list dates you used]. Boulder, Colorado USA: National Snow and Ice Data Center. Digital media.

Craig, A.P., R. Jacob, B. Kauffman, T. Bettge, J. Larson, E. Ong, C. Ding, and Y. He, 2005: CPL6: The new extensible, high performance parallel coupler for the Community Climate System Model. High Perf. Comp. Appl., 19, 309-328.

Gent, P.R., S.G. Yeager, R.B. Neale, S. Levis, and D.A. Bailey, 2009: Improvements in a half degree atmosphere/land version of the CCSM. Clim. Dynamics, 34, 819-833.

Deser, C., R. Tomas, M. Alexander, D. Lawrence, 2010: The Seasonal Atmospheric Response to Projected Arctic Sea Ice Loss in the Late Twenty-First Century. J. Climate, 23, 333-351. doi: 10.1175/2009JCLI3053.1

Hack JJ, Caron JM, Danabasoglu G, Oleson KW, Bitz C, Truesdale JE (2006) CCSM-CAM3 climate simulation sensitivity to changes in horizontal resolution. J Clim 19:2267-2289. doi: 10.1175/JCLI3764.1

Hurrell, J., G. A. Meehl, D. Bader, T. L. Delworth, B. Kirtman, B. Wielicki, 2009: A Unified Modeling Approach to Climate System Prediction. Bull. Amer. Meteor. Soc., 90, 1819-1832.

Jochum M, Danabasoglu G, Holland MM, Kwon YO, Large WG (2008) Ocean viscosity and climate. J Geophys Res 113. doi:10.1029/2007JC004515

Jochum, M., C. Desser, and A. Phillips, 2007: Tropical atmospheric variability forced by oceanic internal variability. J. Climate, 20, 765-771.

Jochum, M. and R. Murtugudde, 2004: Internal variability of the tropical paci_c ocean. Geo. Phys. Res. Lett., 31 (L14309).

Kirtman, B.P., and G. Vecchi, 2010: Why Climate Modelers Should Worry About the Weather. WMO Monograph: The Global Monsoon System: Research and Forecast, 2nd Ed.

Kobayashi C, Sugi M (2004) Impact of horizontal resolution on the simulation of the Asian summer monsoon and tropical cyclones in the JMA global model. Clim Dyn 23:165-176. doi:10.1007/s00382-004-0427-8

May W, Roeckner E (2001) A time-slice experiment with the ECHAM4 AGCM at high resolution: the impact of horizontal resolution on annual mean climate change. Clim Dyn 17:407-420. doi:10.1007/s003820000112

Maloney, E.D. and D.B. Chelton, 2006: An assessment of sea surface temperature influence on surface winds in numerical weather prediction and climate models. J. Climate, 19, 2743-2762.

McClean, J.L., D.C. Bader, F.O. Bryan, M.E. Maltrud, J.M. Dennis, A.A. Mirin, P.W. Jones, M. Vertenstein, D.P. Ivanova, Y.-Y. Kim, J.S. Boyle, R.L. Jacob, N. Norton, A. Craig, and P.H. Worley, 2010:A prototype two-decade fully-coupled fine-resolution CCSM simulation. J. Climate (submitted).

Minobe, S., A. Kuwano-Yoshida, N. Komori, S.-P. Xie, R.J. Small, 2008: Influence of the Gulf 
Stream on the troposphere. Science, 452, doi:10.1038/Nature06690.

Murray, R. 1996: Explicit generation of orthogonal grids for ocean models. J. Comp. Phys., 126, 251-273.

Navarra A et al (2008) Atmospheric horizontal resolution affects tropical climate variability in coupled models. J Clim 21:730- 750. doi:10.1175/2007JCLI1406.1

Neale, R.B., J.H. Richter, M. Jochum, 2008: The impact of convection on ENSO: from a delayed oscillator to a series of events. J. Climate, 21, 5904-5924.

Pope V, Stratton R (2002) The processes governing horizontal resolution sensitivity in a climate model. Clim Dyn 19:211-236. doi:10.1007/s00382-001-0222-8

Randall, D. A., M. Khairoutdinov, A. Arakawa , and W. Grabowski, 2003: Breaking the cloudparameterization dead- lock. Bull. Amer. Meteor. Soc., 84, 1547-1564.

Roberts, M.J., A. Clayton, M.-E. Demory, J. Donners, P.L. Vidale, W. Norton, L. Shaffrey, D.P. Stevens, I Stevens, R.A. Wood and J. Slingo, 2009: Impact of resolution on the tropical Pacific Circulation in a matrix of coupled models. J. Climate, 22, 2541-2556.

Shukla, J., R. Hagedorn, M. Miller, T. N. Palmer, B. Hoskins, J. Kinter, J. Marotzke, J. Slingo, 2009: Strategies: Revolution in Climate Prediction is Both Necessary and Possible: A

Declaration at the World Modelling Summit for Climate Prediction. Bull. Amer. Meteor. Soc., 90, 175-178.

Small, R.J., K.J. Richards, S.-P. Xie, P. Dutrieux, and T. Miyama, 2009: Damping of tropical instability waves caused by the action of surface currents on stress. J. Geophys. Res., 114, C04009, doi:10.1029/2008JC005147.

von Storch J-S (2000) Signature of air-sea interactions in a coupled atmosphere-ocean GCM. J Clim 13:3361-3379

Wu, R., and B. P. Kirtman, 2007: Regimes of local air-sea interactions and implications for performance of forced simulations. Climate Dynamics, 29, 393-410

Wu, R., B. P. Kirtman, K. Pegion, 2006: Local air-sea relationship in observations and model simulations. J. Climate, 19, 4914-4932.

Wu, R., B. P. Kirtman, and K. Pegion, 2007: Surface latent heat flux and its relationship with sea surface temperature in the National Centers for Environmental Prediction Climate Forecast System simulations and retrospective forecasts. Geophys. Res. Lett., 34, L17712, doi:10.1029/2007GL030751. 

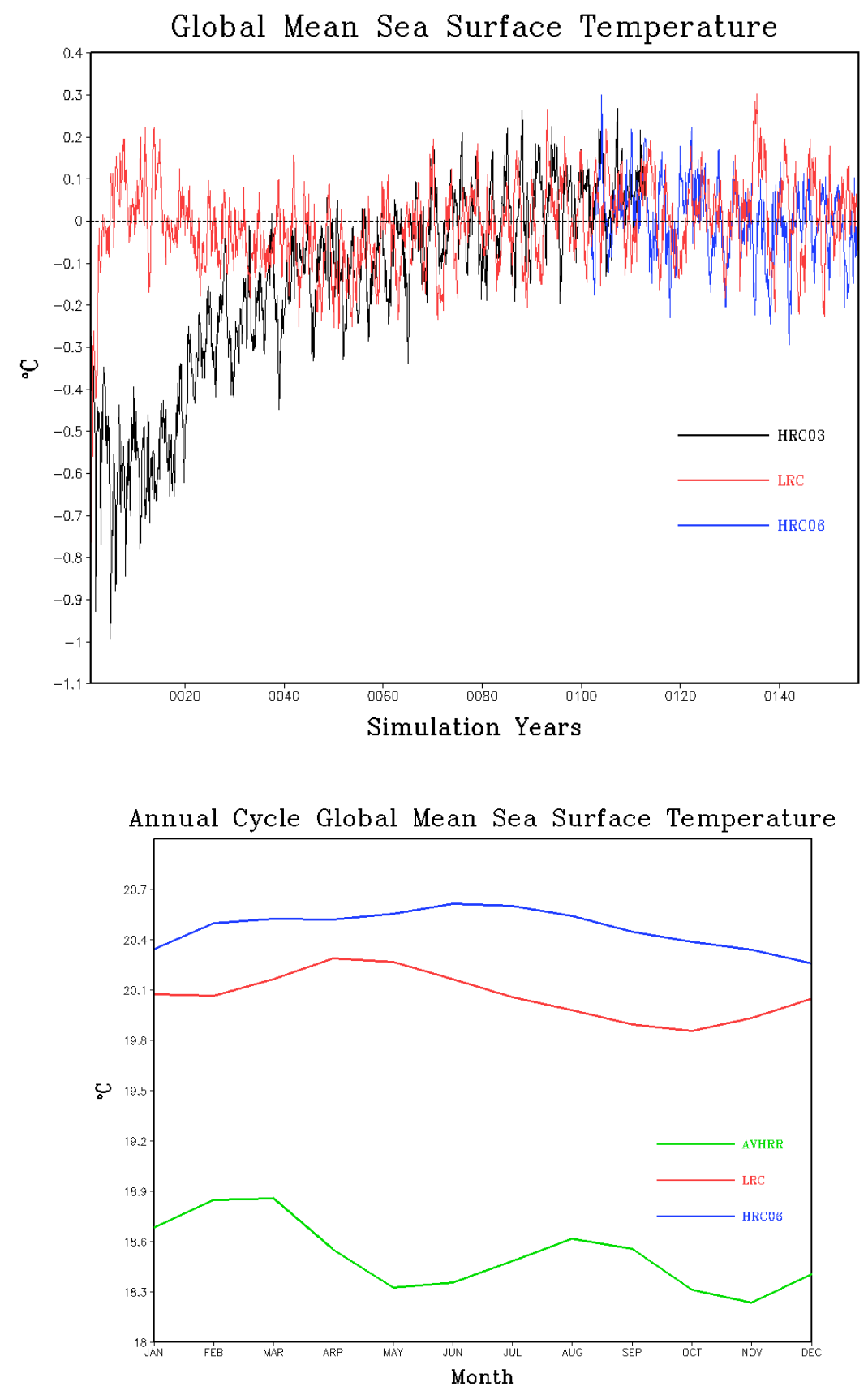

Figure 1: Time evolution of global mean sea surface temperature anomalies (top) for LRC (red), HRC03 (black) and HRC06 (blue). The anomaly is defined as the deviation from the climatology based on the last 50-years of each respective simulation. The bottom panel shows the last 50year monthly mean climatology from LRC (red), HRC06 (blue) and AVHRR Climatology (green). 

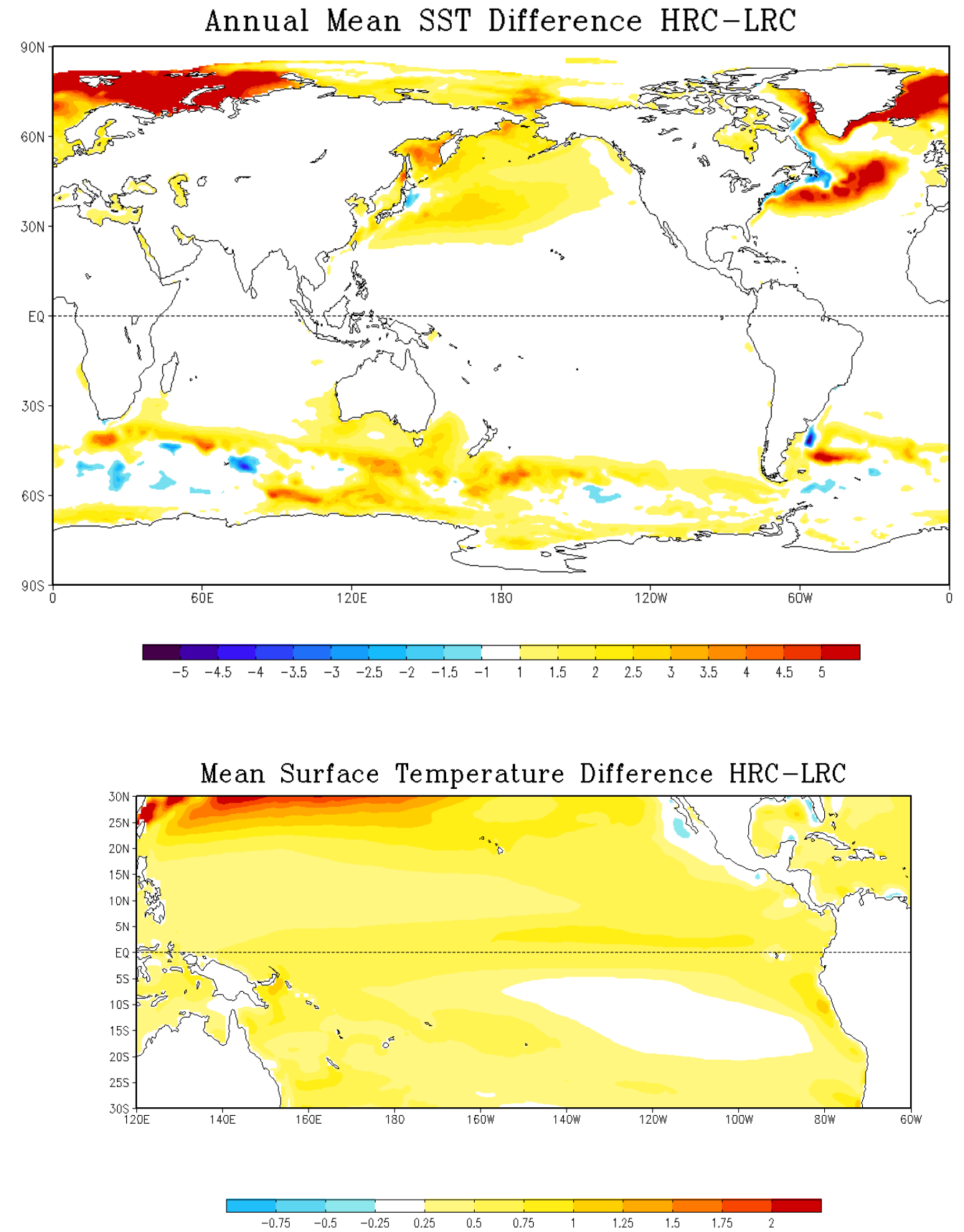

Figure 2: Annual mean surface temperature difference (HRC06-LRC) for the whole globe (top) and for the tropical Pacific (bottom). Contour is in degrees Celsius. 

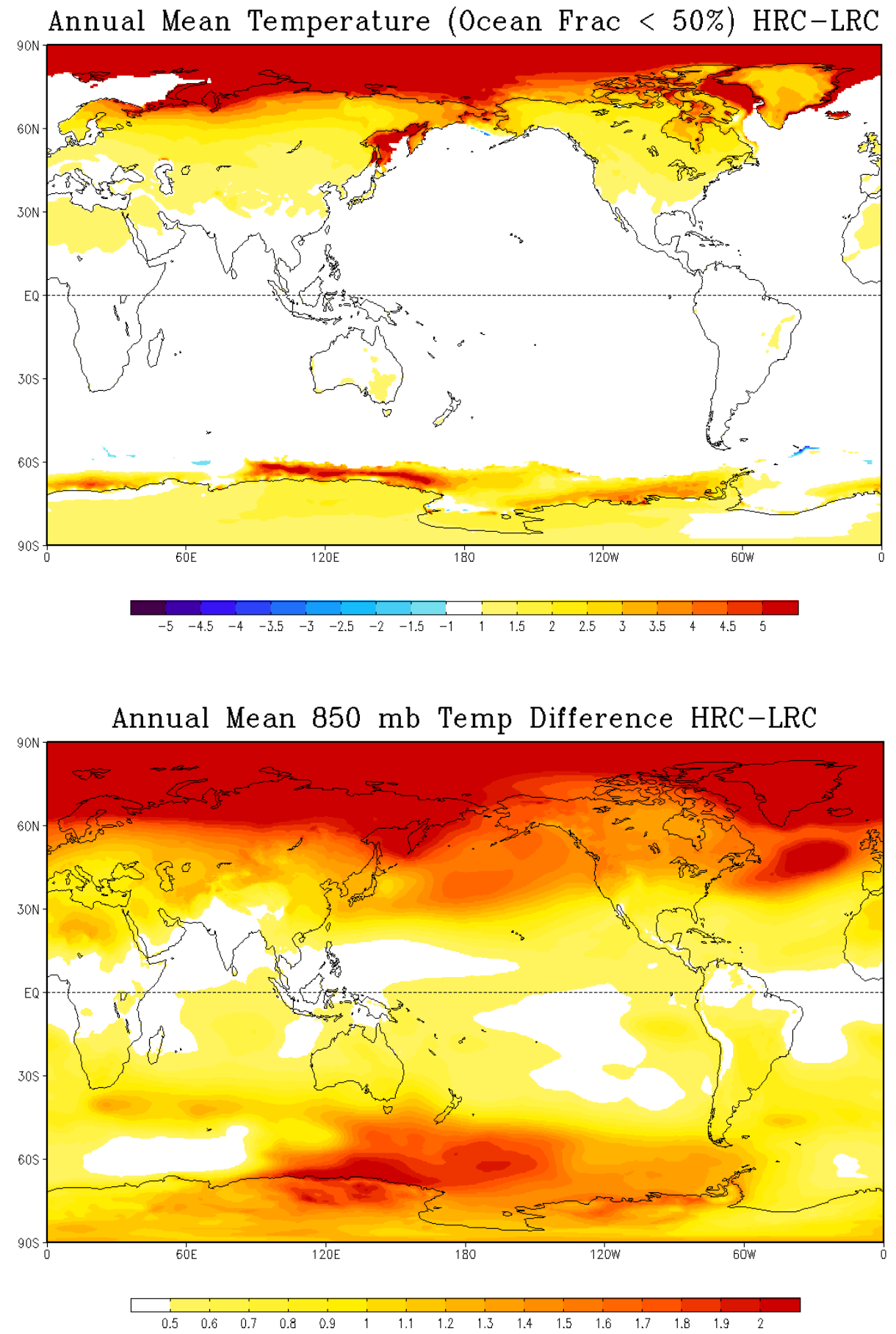

Figure 3: (Top) Annual mean surface temperature (fractional land and sea ice coverage greater than $50 \%$ in a grid cell) difference (HRC06-LRC). (Bottom) Annual mean $850 \mathrm{mb}$ temperature difference (HRC06-LRC). Contours in degrees Celsius. 

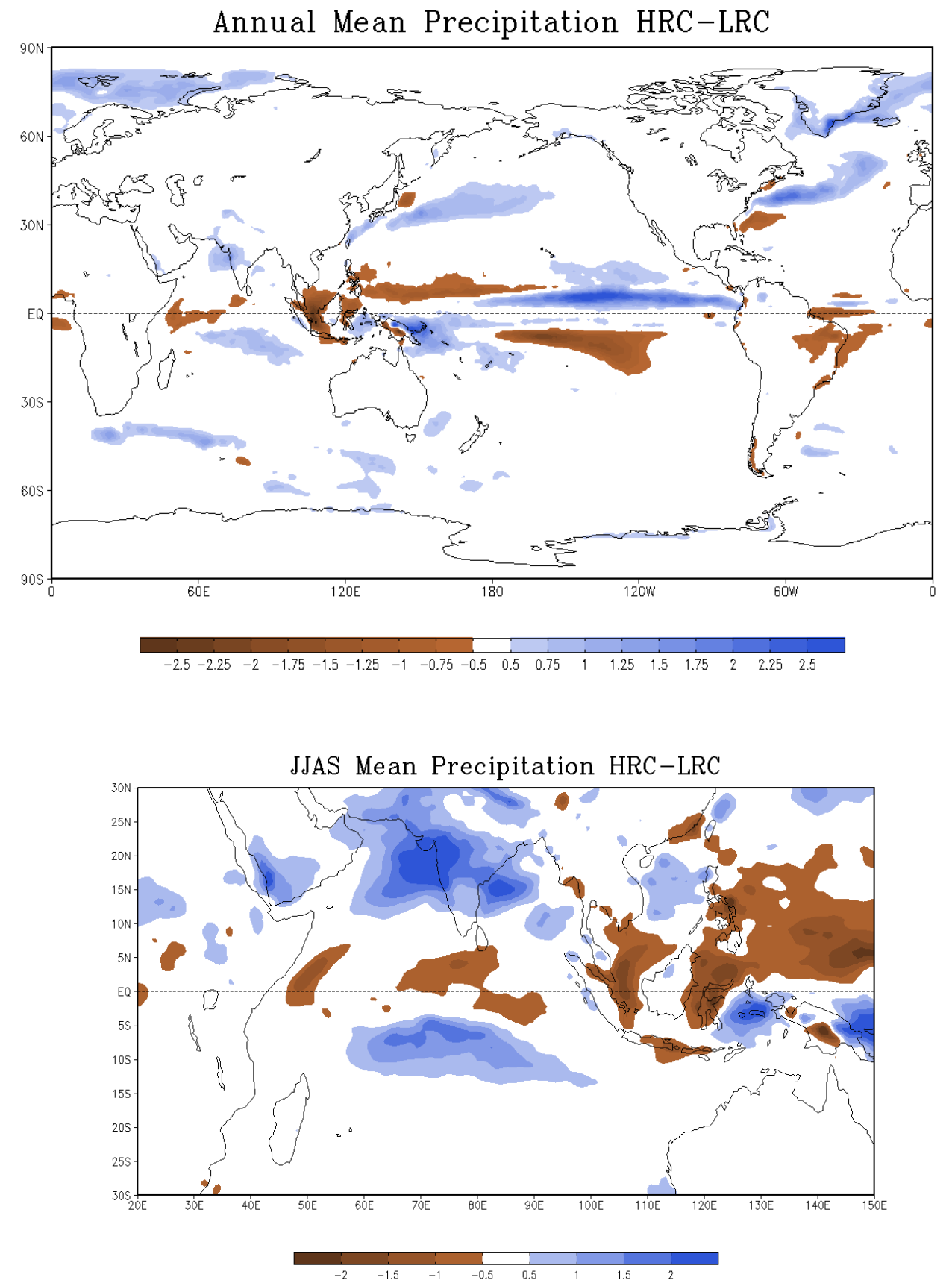

Figure 4: (Top) Annual mean precipitation difference (HRC06-LRC) globally. (Bottom) JuneSeptember mean precipitation (HRC06-LRC) difference in the Austral-Asian Monsoon region. Contours in $\mathrm{mm}_{\text {day }}{ }^{-1}$. 


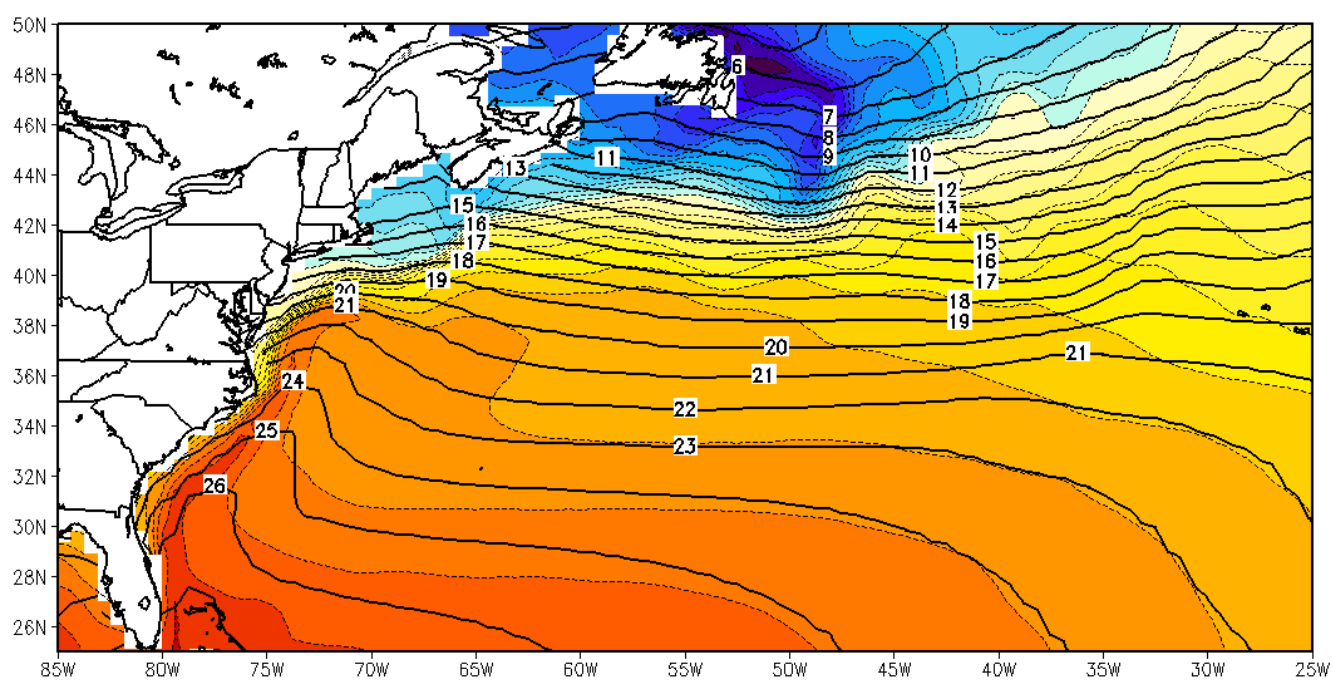

$\begin{array}{llllllllllllllllllllllllll}3 & 4 & 5 & 6 & 7 & 8 & 9 & 10 & 11 & 12 & 13 & 14 & 15 & 16 & 17 & 18 & 19 & 20 & 21 & 22 & 23 & 24 & 25 & 26 & 27 & 28\end{array}$
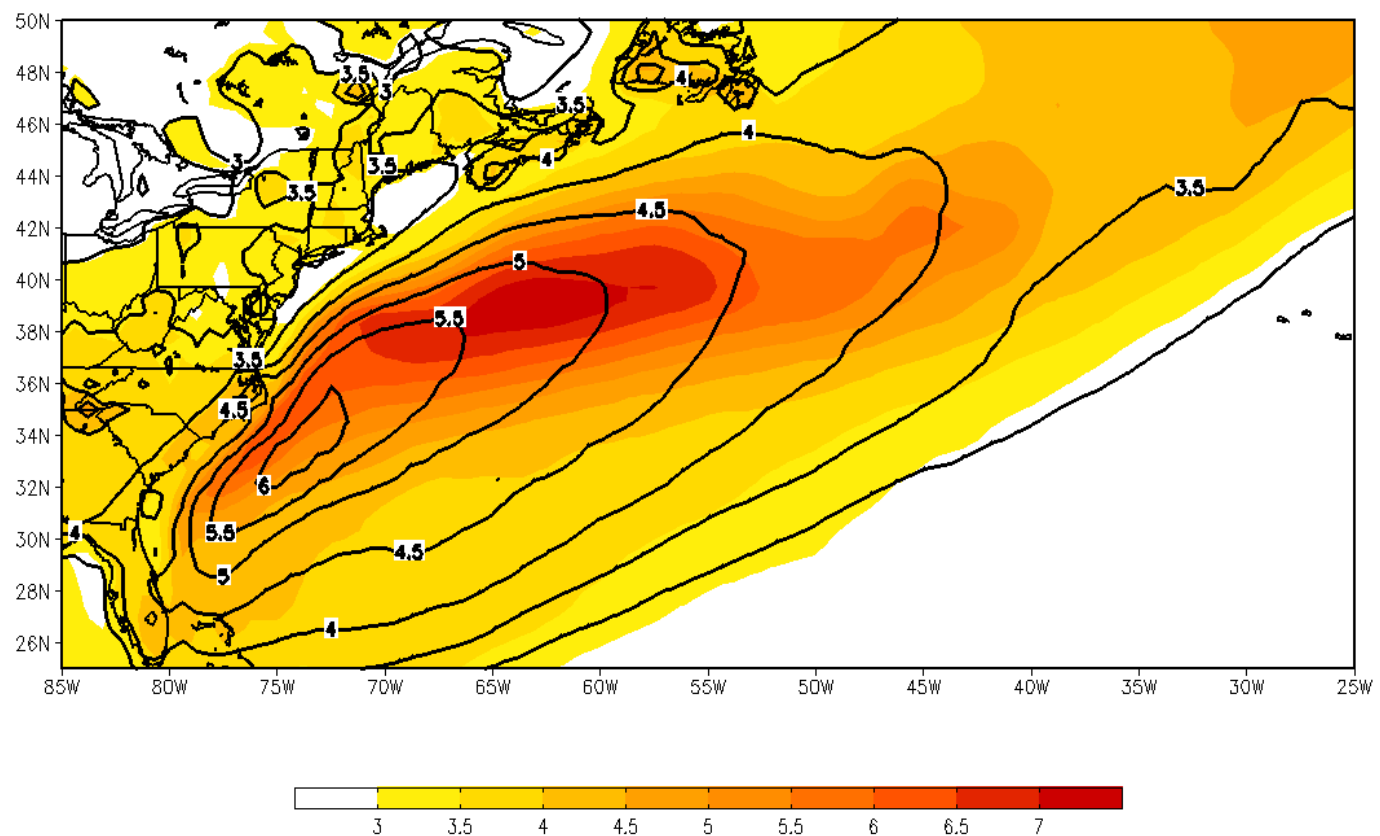


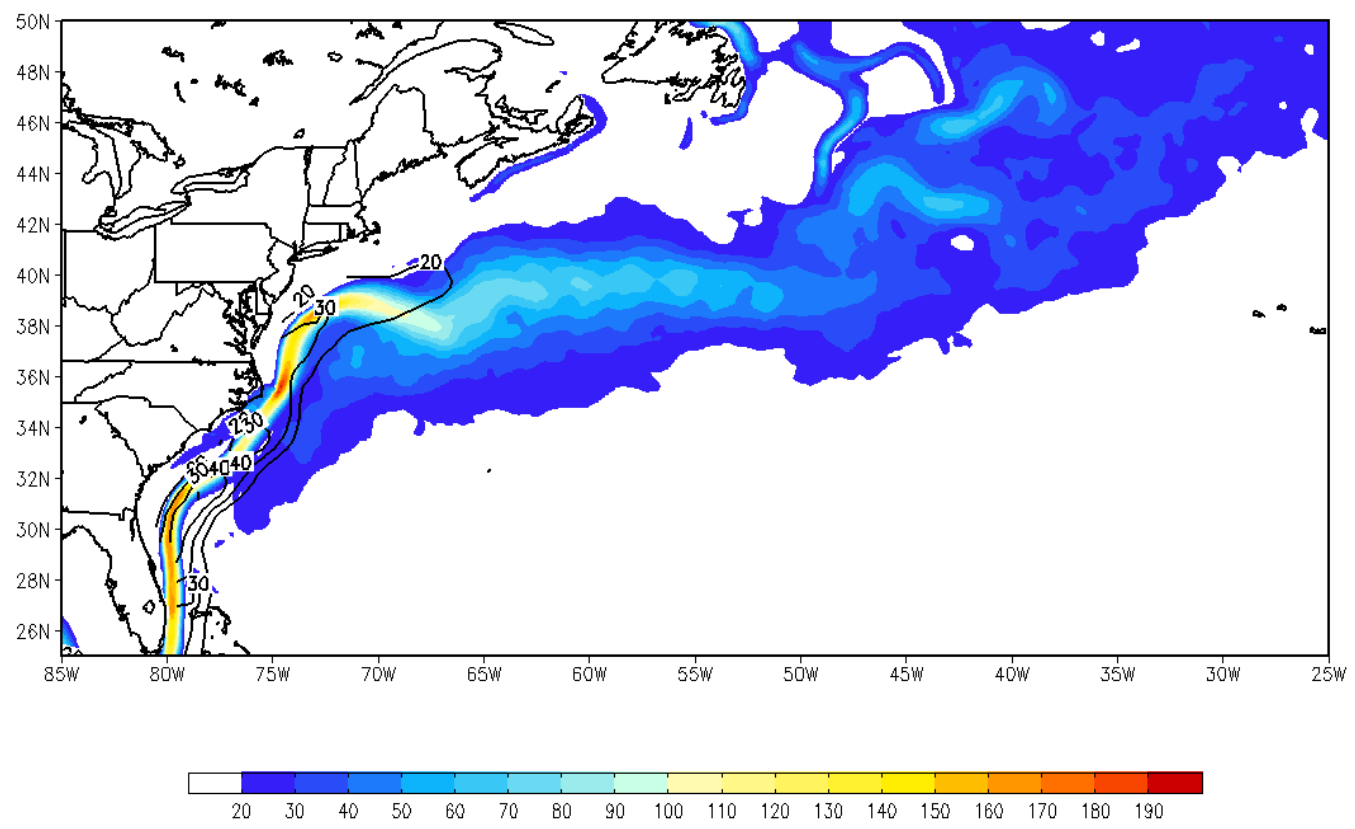

Figure 5: (Top) Annual mean SST in the North Atlantic for HRC06 (shaded) and for LRC (contour) in degrees Celsius. (Middle) Annual mean precipitation in the North Atlantic for HRC06 (shaded) and for LRC (contours) in $\mathrm{mm} \mathrm{day}^{-1}$. (Bottom) Annual mean surface current speeds in $\mathrm{cm} \mathrm{sec}^{-1}$ for HRC (shaded) and LRC (contour). 

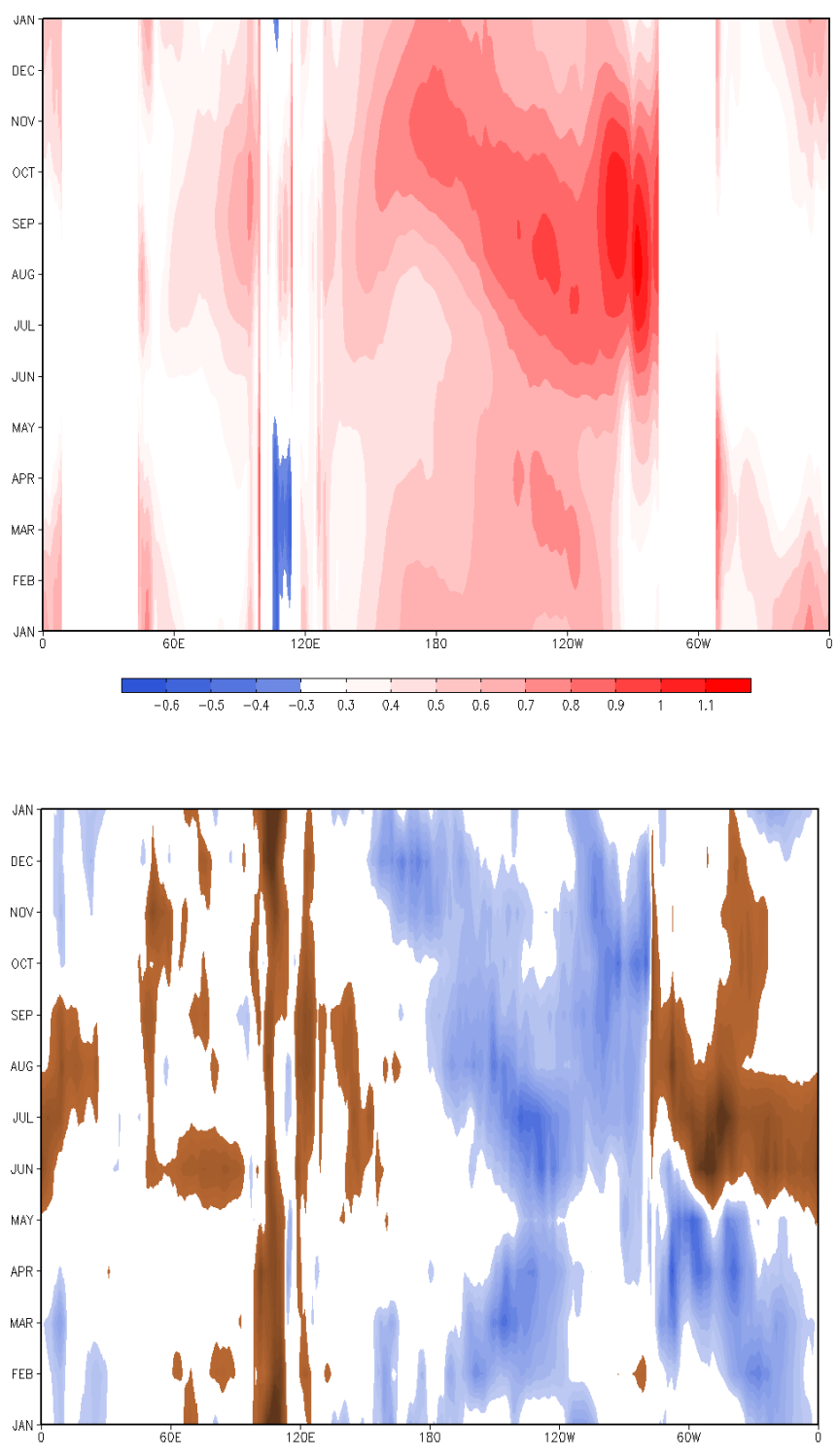

$-3-2.8-2.6-2.4-2.2-2-1.8-1.6-1.4-1.2-1-0.8-0.60 .60 .8 \quad 1 \quad 1.21 .41 .61 .8222 .22 .42 .62 .8$

Figure 6: (Top) Difference (HRC06-LRC) in the time-longitude evolution of the mean annual cycle of SST averaged from 0-5N in degrees Celsius. (Bottom) Difference (HRC06-LRC) in the time-longitude evolution of the mean annual cycle of precipitation averaged from $0-5 \mathrm{~N}$ in mm day $^{-1}$. 

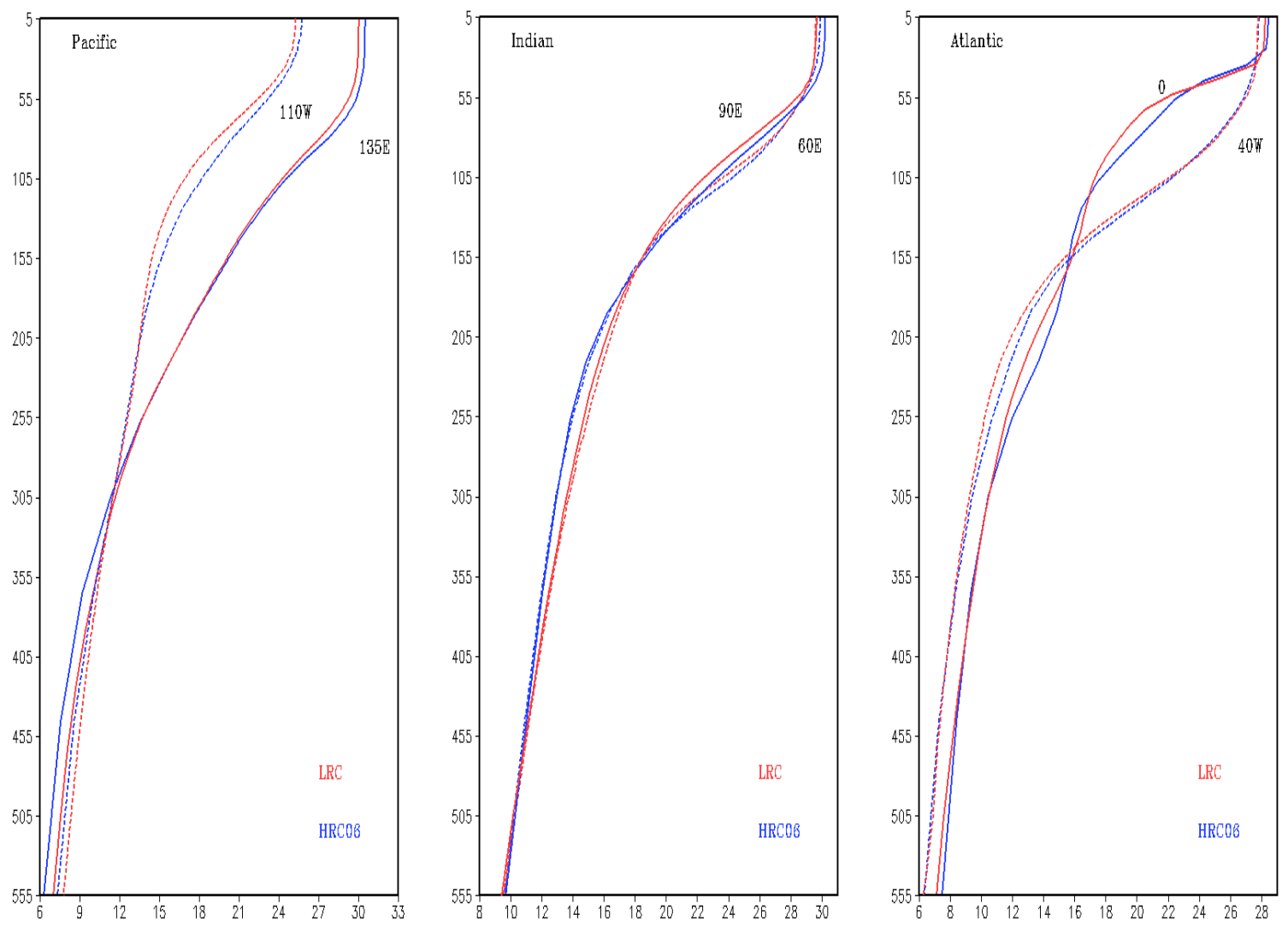

Figure 7: Vertical structure of near equatorial temperatures (1S-1N average) from HRC06 (blue) and LRC (red) in degrees Celsius for selected locations in the Pacific, Indian and Atlantic Oceans. 

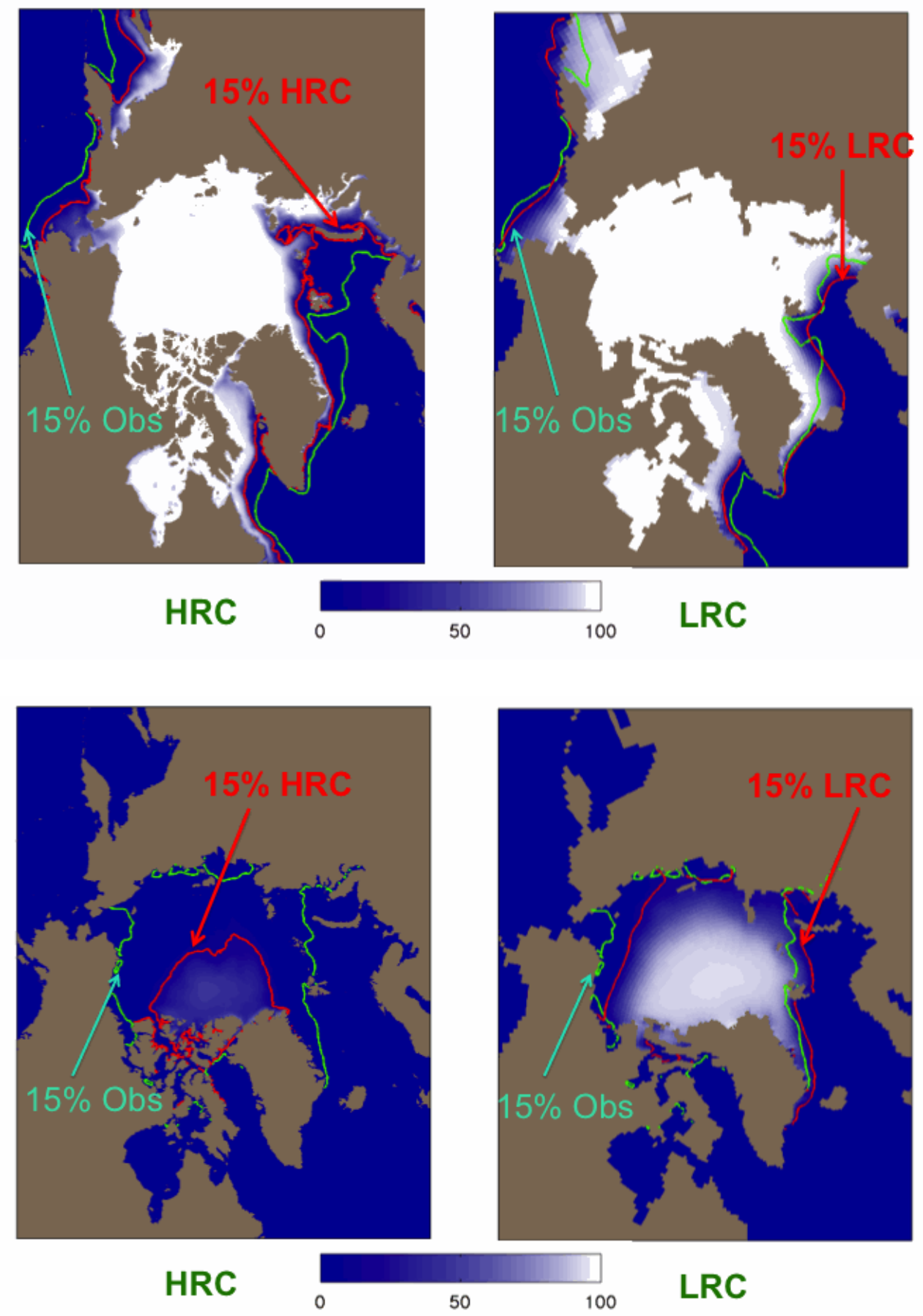

Figure 8: Arctic sea ice concentration in March (upper panels) and September (lower panels) for HRC and LRC runs. The $15 \%$ concentration contour from the model is shown in red and from observations in green. Observations are from passive microwave averaged 1979-1999 (Comiso, 1999). 

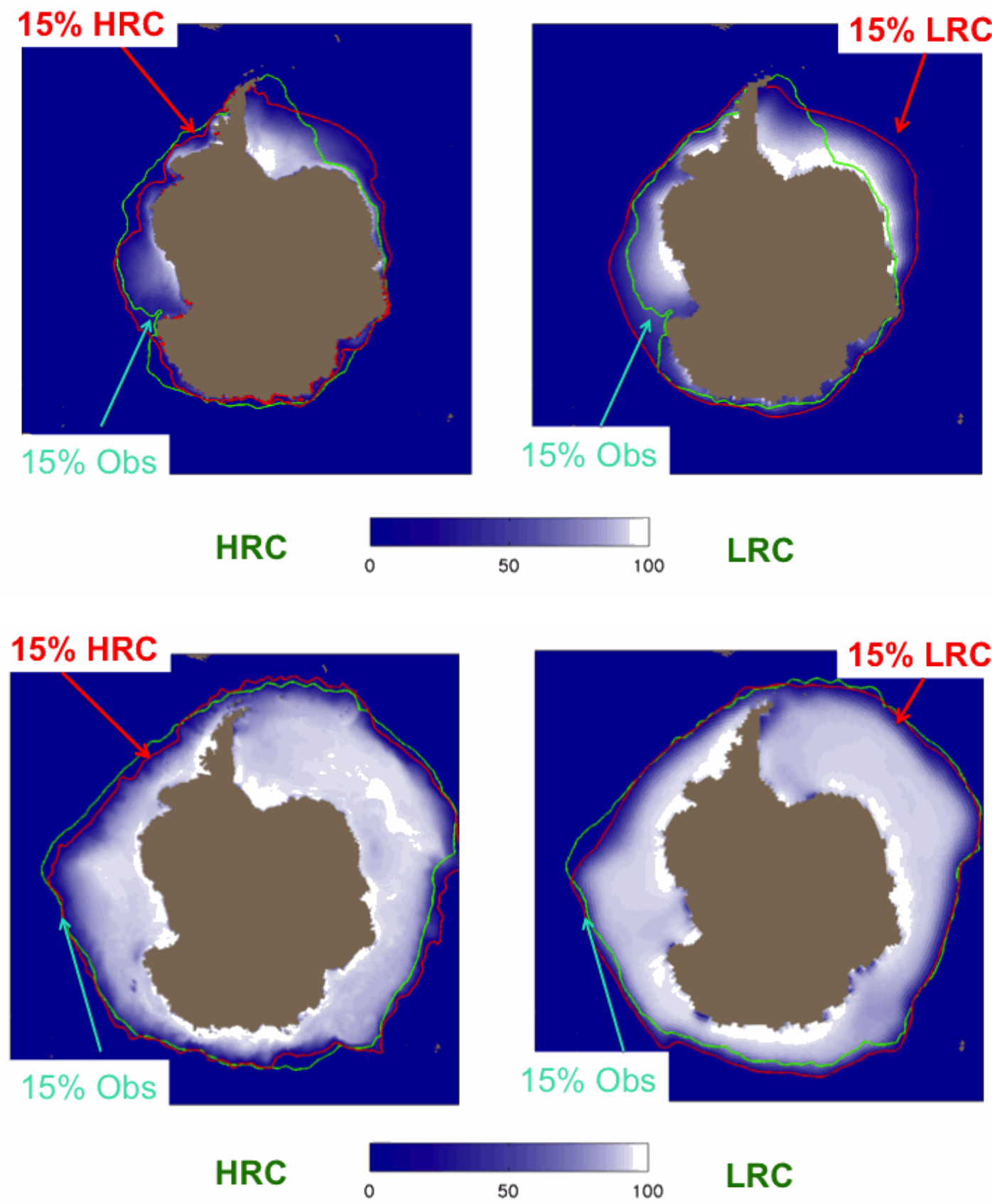

Fig 9. As for Fig 8, but for Antarctic. 
Surface Temperature Standard Deviation Ratio HRC/LRC
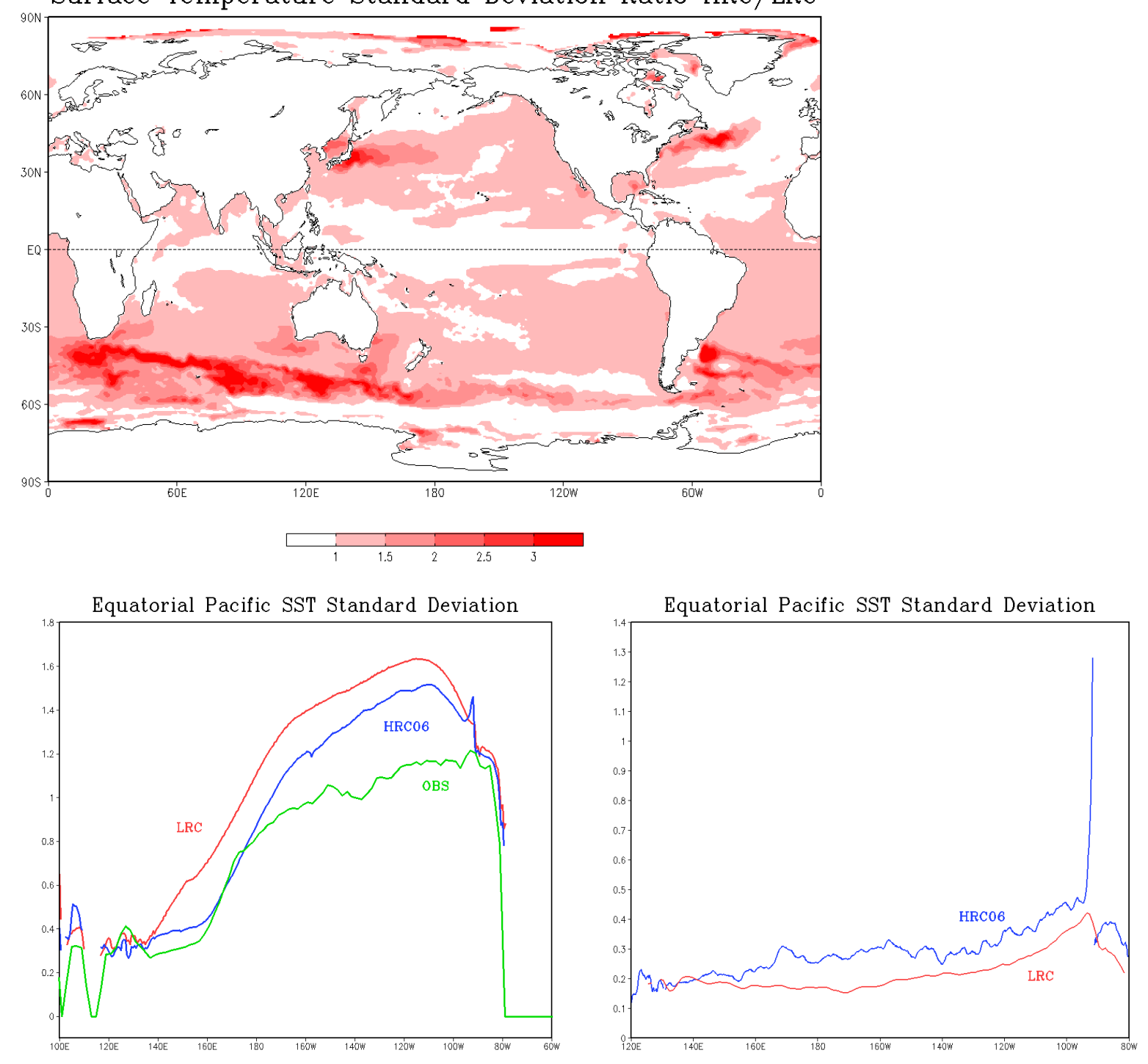

Figure 10: (Top) SSTA monthly mean standard deviation ratio (HRC06/LRC) - dimensionless. Values greater than 1.0 indicate more variance in HRC06. (Bottom left) SSTA monthly mean standard deviation near the equator (1S-1N) in the Pacific for LRC (red) and HRC06 (blue) in degrees Celsius. Observational estimates are given in green. (Bottom right) SSTA high pass filtered SSTA standard deviation near the equator (1S-1N) in the Pacific for LRC (red) and HRC06 (blue). 

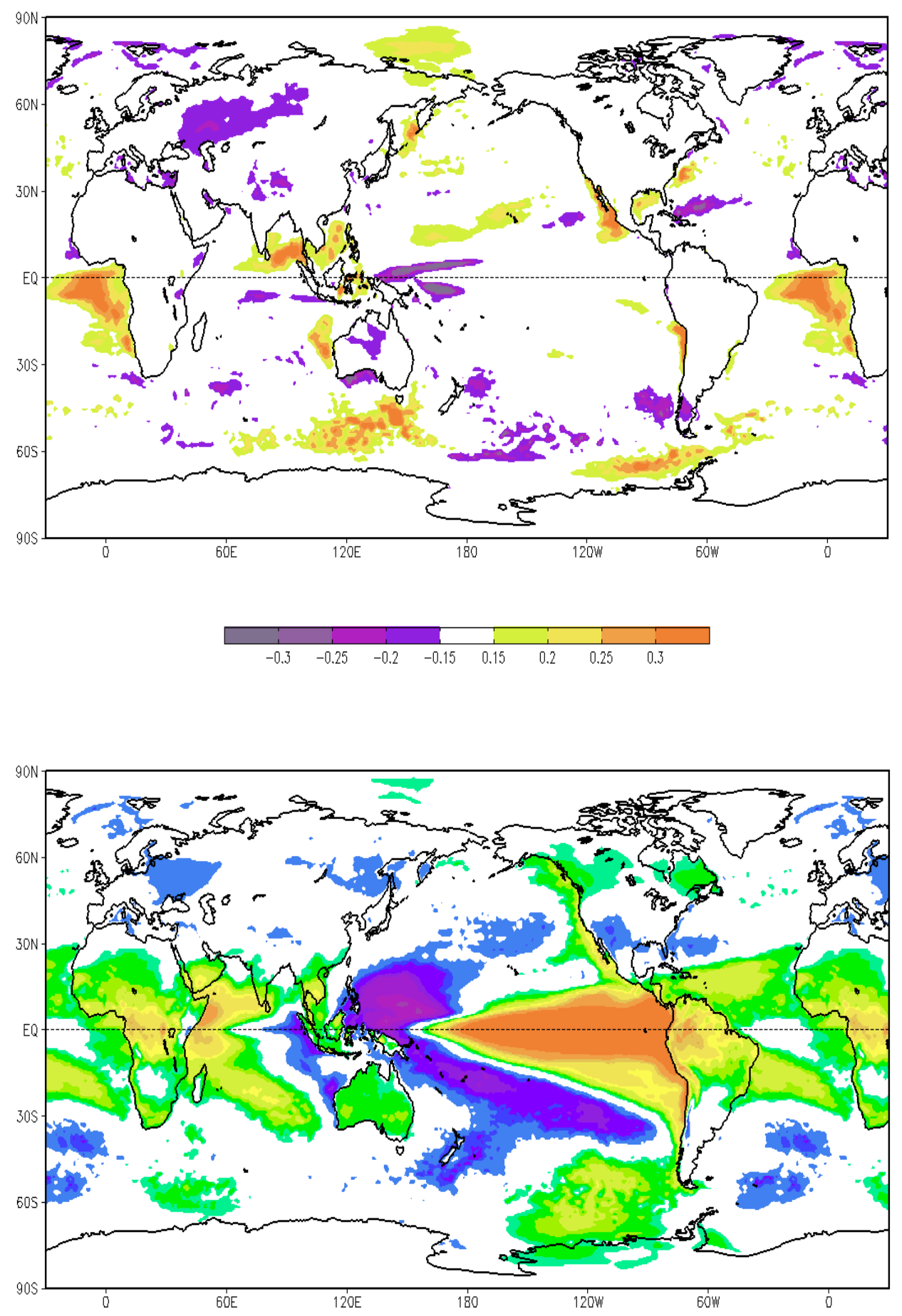

$\begin{array}{llllllllllllllll}-0.6 & -0.55 & -0.45 & -0.4 & -0.3 & -0.25 & -0.15 & 0.15 & 0.2 & 0.3 & 0.35 & 0.45 & 0.5 & 0.6 & 0.65 & 0.75\end{array}$

Figure 11: NINO34-SSTA point correlation map calculated for years 102-155. Top panel shows the difference HRC06-LRC and the bottom panel shows the results for HRC06. 

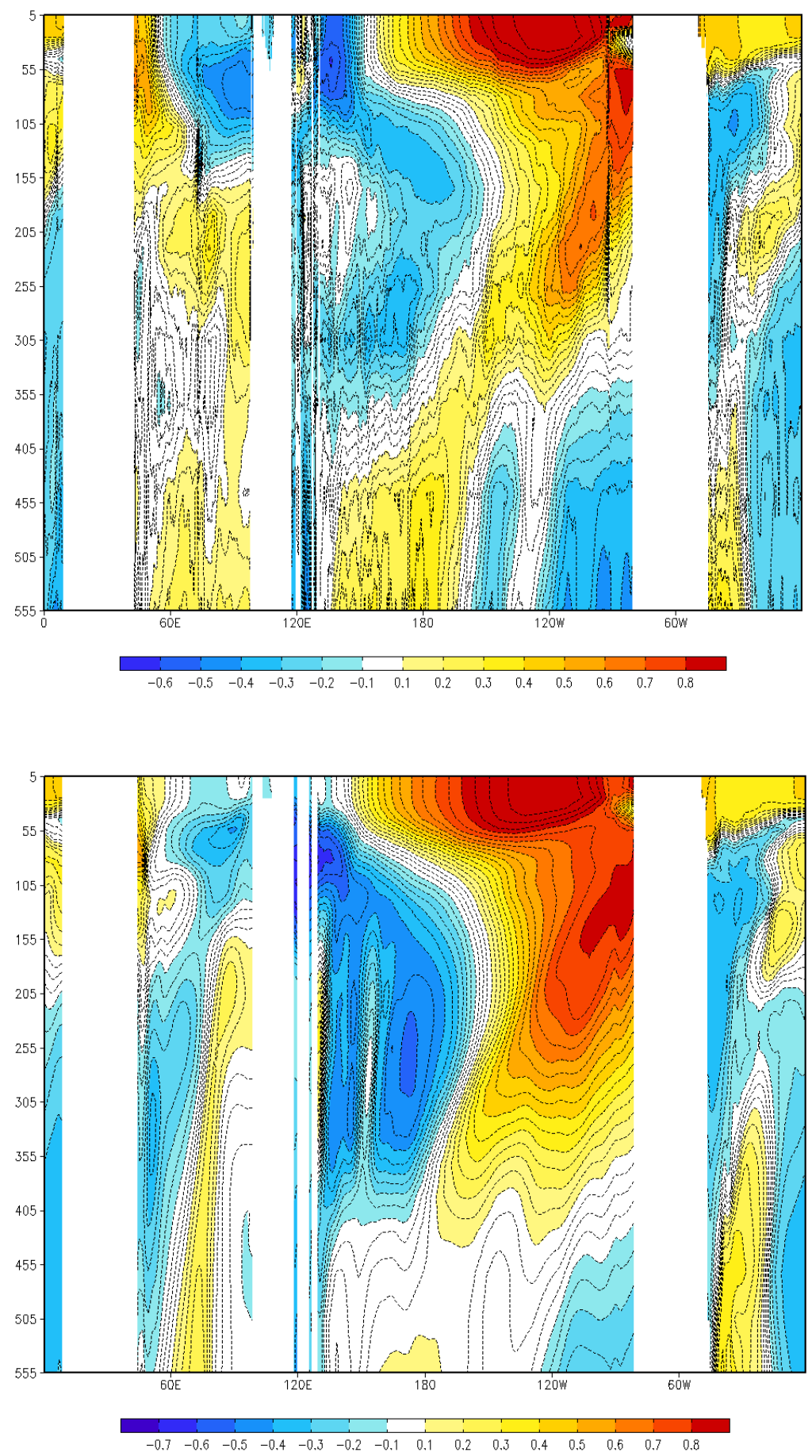

Figure 12 NINO34 - equatorial ocean temperature anomaly correlation map as a function of longitude and depth calculated for year 102-155. HRC06 is the top panel and LRC is bottom panel. 

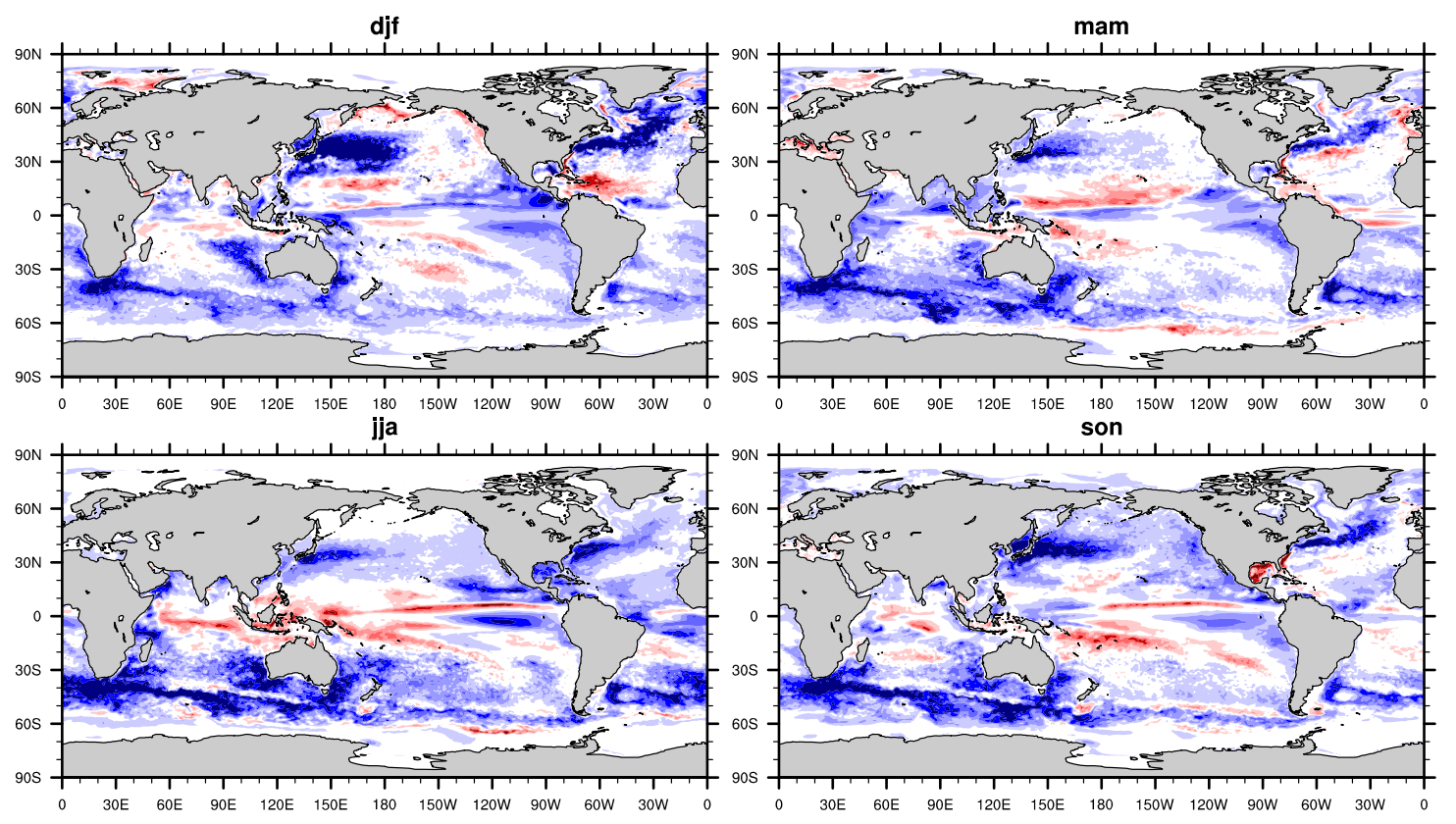

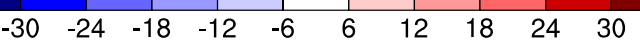

Figure 13: The local regression of the seasonal mean detrended turbulent heat flux anomalies (latent + sensible) onto the detrended SSTA for HRC06 (last 50 years). Contours are every 6 Wm-2/deg C. 

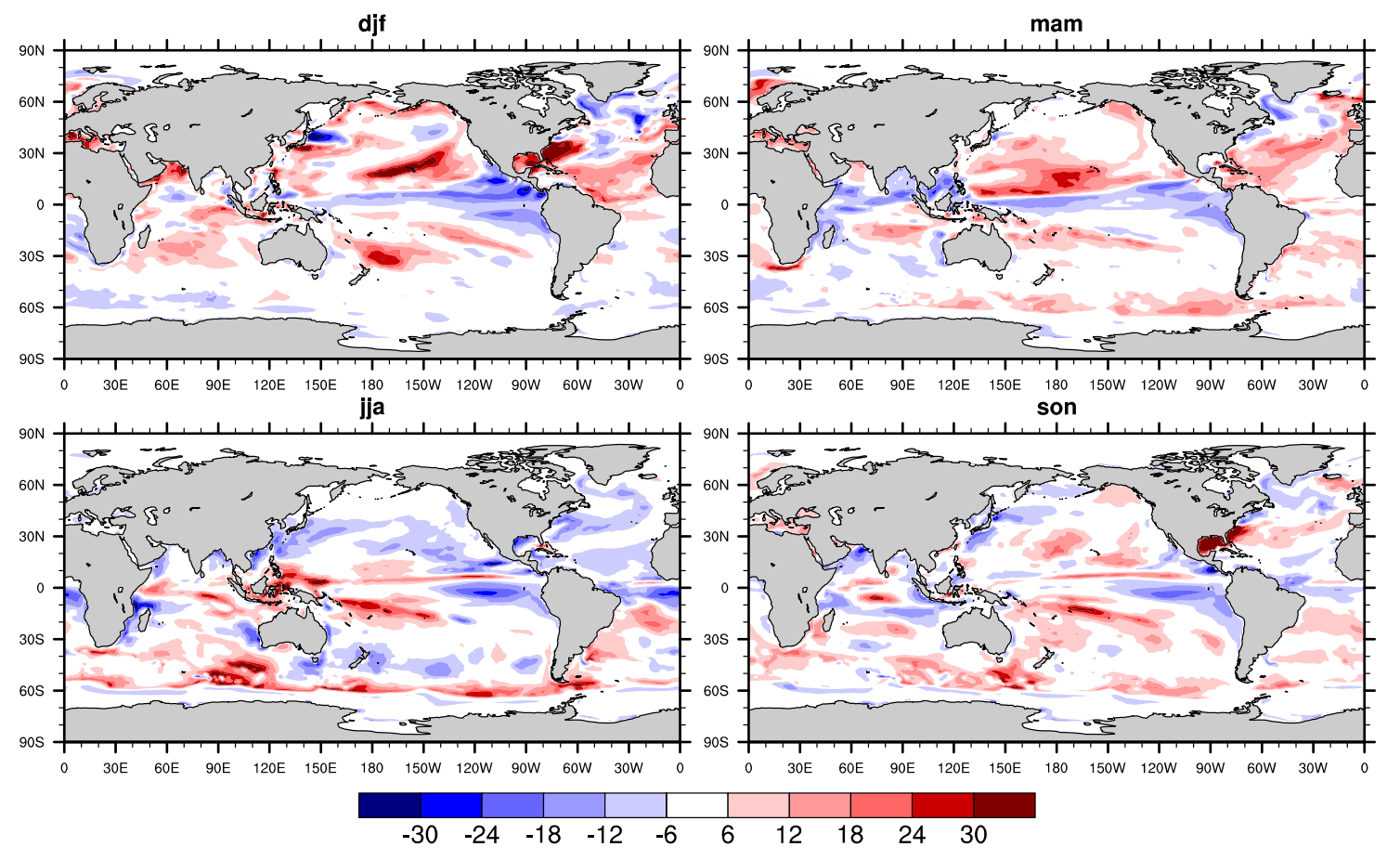

Figure 14: Same as Fig. 13 except for LRC. 